upf. $\begin{array}{ll}\text { Universitat } \\ \text { Pompeu Fabra } \\ \text { Barcelona }\end{array} \quad \begin{aligned} & \text { Department } \\ & \text { of Economics and Business }\end{aligned}$

Economics Working Paper Series

Working Paper No. 1612

\title{
Common ownership and market entry: evidence from the pharmaceutical industry
}

Melisa Newham, Jo Seldeslachts and Albert Banal-Estañol

May 2018 


\title{
Common Ownership and Market Entry: Evidence from the Pharmaceutical Industry*
}

\author{
Melissa Newham ${ }^{\dagger}$ \\ Jo Seldeslachts ${ }^{\ddagger}$ \\ Albert Banal-Estanol ${ }^{\S}$
}

May 2018

\begin{abstract}
Common ownership - where two firms are at least partially owned by the same investor - and its impact on product market outcomes has recently drawn a lot of attention from scholars and practitioners alike. Theoretical and empirical research suggests that common ownership can lead to higher prices. This paper focuses on implications for market entry. To estimate the effect of common ownership on entry decisions, we focus on the pharmaceutical industry. In particular, we consider the entry decisions of generic pharmaceutical firms into drug markets opened up by the end of regulatory protection in the US. We first provide a theoretical framework that shows that a higher level of common ownership between the brand firm (incumbent) and potential generic entrant reduces the generic's incentives to entry. We provide robust evidence for this prediction. The effect is large: a one-standard-deviation increase in common ownership decreases the probability of generic entry by $9-13 \%$. We extend our basic theoretical framework and allow for multiple entrants. Our model shows that for sufficiently high levels of common ownership, the classical idea of entry decisions being strategic substitutes can be reversed into being strategic complements. Our empirical results provide some support for these predictions.
\end{abstract}

JEL-code: G23, K21, L11, L41, L65

Key words: Market Entry, Ownership Structure, Pharma

${ }^{*}$ All co-authors contributed equally to this paper. We thank Martin Schmalz for helpful comments. We further benefitted from people's comments at DIW Berlin, KU Leuven, LMU Munich, Pompeu Fabra, University of Johannesburg, and University of Stellenbosch. We like to thank Anna Sama and especially Julian Hidalgo for their excellent research assistance.

${ }^{\dagger}$ KU Leuven and DIW Berlin. Email: melissa.newham@kuleuven.be

${ }^{\ddagger}$ Corresponding author. KU Leuven and DIW Berlin. Email: jo.seldeslachts@kuleuven.be. Seldeslachts acknowledges financial support from the Flemish Science Foundation (FWO).

${ }^{\S}$ Universitat Pompeu Fabra and City University London. Email: albert.banalestanol@upf.edu. Banal-Estanol acknowledges financial support from the Spanish Ministry of Economy and Competitiveness, through the Severo Ochoa Programme for Centres of Excellence in R\&D (SEV-2015-0563) and project ECO2016-76998-P and from the Fundacin Ramn Areces (CISP15S3712). 


\section{Introduction}

BlackRock and Vanguard, the world's largest institutional investors, are the top two shareholders in Johnson \& Johnson, Pfizer, Abbott Laboratories, Perrigo, and Allergan, which are clearly competitors in the US pharmaceutical markets (Thomson Reuters Global Ownership Database, 2015). ${ }^{1}$ Investors' holdings in multiple firms gives rise to "common ownership." When firms are largely owned or influenced by shareholders who also have sizeable stakes in competitors and act in these shareholders' interest, then rather than maximizing their own value, commonly-owned firms should maximize the return to their shareholders i.e. their portfolio values. ${ }^{2}$ Thus firms' connectivity through investor shareholdings may alter their strategic decisions.

The focus of this paper is on the effect of common ownership on one of the most important strategic decisions firms make: entry. Specifically, we analyse generic firms' entry decisions into pharmaceutical markets opened up by the end of regulatory protection. Patent-protected markets are a vital source of revenue for brand firms. With the event of generic entry, revenues to the brand firms can decline by as much as $90 \%$ (Bransetter et al., 2016). Moreover, losses to the brand and gains to the generic are highly asymmetric. According to one estimate, brand firms value deterring entry, on average, at about $\$ 4.6$ billion. In contrast, generic firms value the right to enter at about $\$ 236.8$ million (Jacobo-Rubio et al., 2017). Thus, generic firms' entry decisions may crucially depend on whether investors in a potential generic entrant also have an interest in the brand (incumbent).

We show that a higher level of common ownership between a brand firm and a potential generic entrant is robustly linked with a lower probability of generic entry. To do so we combine patent and drug approval data from the US Food and Drug Administration's (FDA) Orange Book with ownership data of publicly listed pharmaceutical companies from the Thomson Reuters Global Ownership Database. Apart from the facts mentioned above, the US pharmaceutical industry is an attractive industry to consider in this context because; (i) US health care expenditure as a percentage of GDP is among the highest in the world and generic medicines are crucial to keeping down healthcare costs, (ii) pharmaceutical markets are well defined and (iii) one can identify clear entry windows.

In this paper we first present a simple theoretical framework to understand the effects of common ownership between an incumbent and a potential entrant. Thereafter

\footnotetext{
${ }^{1}$ Institutional investors such as Blackrock and Vanguard manage other people's money by buying and controlling equity in companies.

${ }^{2}$ See Schmalz (2018) for a review of the available evidence.
} 
we empirically test and corroborate the proposition that higher common ownership between a brand and a generic firm reduces the incentives to enter of the generic firm. This result is robust to a wide range of measures of common ownership, different econometric specifications, different definitions of the set of potential entrants and different time-horizons of the decision-making process. Our regressions include the controls used in previous literature including pre-entry brand sales, on-patent molecular substitutes, entrant experience and the presence of authorised generic. The effect is large: a one-standard-deviation increase common ownership decreases the probability of generic entry by $9-13 \%$. Our results are even stronger if we instrument the common ownership measures with stock market index membership or company headquarters location. Still, the effect of a generic firm's common ownership with the brand firm is smaller than the effect of being a subsidiary of the brand company.

We extend the basic framework to take into account that several generic firms may be simultaneously deciding whether to enter the market of the same brand firm. We show that the classical result of entry decisions being strategic substitutes may be reversed in the presence of common ownership. Entry decisions become strategic complements -i.e. a focal generic firm's entry is less likely when another generic's probability of entry decreases- when the degree of common ownership is high. As a result, for low levels of common ownership, entry decisions are strategic substitutes but, when the levels of common ownership are large, entry decisions are strategic complements. Our empirical results provide some support for these predictions.

Common ownership linkages created by institutional investors is a pervasive feature not only of pharmaceutical companies, but of many industries in the US as well as in Europe (Fichtner et al., 2017). While large institutional investors may own 5-8\% of a single company, this is normally enough to position them as a top investor with privileged access to the firms' management (Malenko and Shen, 2016). Furthermore, and contrary to others, "passive" institutional investors who primarily offer funds that track an index are also less willing - or are more restricted - to divest their positions in poorly performing stocks. Therefore, they might be more motivated than other investors to be engaged owners (e.g., Carleton et al., 1998). Managers, in turn, might be more inclined to listen as well, as the stakes of these investors are sizeable and tend to exhibit lower turnover rates (Del Guercio and Hawkins, 1999). ${ }^{3}$ Thus, passive investors

\footnotetext{
${ }^{3}$ The investment strategy of tracking an index is commonly termed "passive" investing. There are also many other institutional investors, such as hedge funds, that pursue mostly "active" investing strategies in the sense that they actively buy and sell companies, however these investors are much less diversified and hence less likely to possess stakes in several companies in the same industry, see Banal-Estanol et al. (2018).
} 
are not passive owners (Appel et al., 2016). ${ }^{4}$

There is indeed growing academic evidence that large institutional investors engage in active discussions with companies' board and management with a view to influence the companies' long-term strategies (e.g., McCahery, 2016; Fichtner and GarciaBernardo, 2017)..$^{5}$ Moreover, there is no requirement that institutional investors with common ownership need to actively influence companies to have an effect on firm strategies. They may have an effect simply by crowding out and occasionally voting against activist investors (Antón et al., 2018).

The ongoing concentration of ownership in the hands of a few large investors and the corresponding escalation in common ownership is unprecedented. It is the defining feature of the firm ownership structures in the present-day. Dubbed "an economic blockbuster" and "the major new antitrust challenge of our time", common ownership is undoubtedly an important, new topic in economics (Elhauge, 2016; Posner et al., 2017). The issue has received significant media attention and instigated public debate; see e.g. The Economist (2015), The New York Times (2016), Handelsblatt Global (2016) and OECD (2017).

Empirical research on the topic is still in its infancy. For a large sample of US public firms, He and Huang (2017) find that common ownership by institutional investors facilitates explicit forms of product market coordination which in turn improves innovation productivity and operating profitability. Azar et al. (2018), on the other hand, provide the first empirical evidence that common ownership in the airline industry is correlated with higher prices. The results of these studies have been subject to ongoing debate. Certain scholars maintain that large institutional investors do not have material influence on market outcomes and that there is no robust causal link between common ownership and firms' strategies (O'Brien and Waehrer, 2017). There is, however, a resounding agreement that more research is required to understand the strategic benefits and profit implications of common ownership (O'Brien and Waehrer, 2017; Patel, 2017; OECD, 2017).

This paper is the first to directly consider the influence of common ownership on market entry. Whereas pricing decisions are typically made on a regular basis by specialised pricing teams, market entry is a once-off decision with substantial consequences for the firm. Hence, and consistent with the results of the paper, we expect significant shareholder involvement in those decisions, and thus a pervasive effect of common ownership. Simultaneous research by Xie and Gerakos (2018) consider how ownership

\footnotetext{
${ }^{4}$ While large institutional investors such as BlackRock and Vanguard are typically considered to be passive investors they also engage in a degree of active investing (Fichtner et al., 2017).

${ }^{5}$ We show in an Appendix that investors confirm this view, both in general and for pharma markets.
} 
linkages through institutional shareholdings affect patent settlements between brand and generic firms. Hence, their study is complementary to this paper. They find that institutional cross-holdings between a brand and generic are significantly positively associated with the likelihood that the two parties will enter into a settlement agreement in which the brand pays the generic to stay out of the market.

The rest of the paper is organised as follows. Section 2 gives a literature overview of entry in pharmaceutical markets and common ownership. Section 3 introduces the basic theoretical framework. Section 4 presents data and variable construction. Section 5 describes the empirical implementation. Section 6 presents and discusses the results. Section 7 extends the framework to multiple entrants. Section 9 concludes. We further include Appendices on data construction, anecdotal evidence on how institutional investors influence firms' decisions and empirical robustness checks.

\section{Literature}

\subsection{Entry in pharma}

Several papers have considered the determinants of generic entry decisions in off-patent drug markets, i.e., markets where the patent of the brand company has expired. A common finding from this literature is that generic entry increases with the size of the branded drugs market prior to the loss of patent protection, where 'size' is measured as brand-generated revenues (Scott Morton, 1999, 2000; Hudson, 2000; Saha et al., 2006; Moreno-Torres et al., 2008; Appelt, 2015).

Scott Morton (1999) further considers other aspects of generic entry decisions in US pharma markets in-depth and finds that generic firms are more likely to enter markets in which they have previous experience e.g. in drug form, therapy class or ingredient. Kyle (2006) and Appelt (2015) similarly confirm the importance of generic firm characteristics. Scott Morton (2000) examines the effect of pre-patent expiration brand advertising expenditures on the number of generic entrants in the US, and finds no evidence that brand advertising impacts generic entry. Scott Morton (1999, 2000) also finds that drugs that treat chronic conditions attract more generic entry and that generic entry is influenced by drug form; generic entry of oral solids tends to be more extensive than that of injectables. Appelt (2015) considers the impact of authorised generics, i.e., the distribution and marketing of the brand product under a generic label through a subsidiary or authorised generic distributor (typically just before the loss of the patent). Using a sample of 73 off-patent drug markets between the years 2002 and 
2007 in Germany, she finds that authorised generic entry has no significant effect on the likelihood of generic entry. Other studies have considered the effect of a brand's stock of goodwill and the duration that a brand is on the market without generic competition, with opposing results (Hurwitz and Caves, 1988; Hudson, 2000, Appelt, 2015).

Most relevant for this study, is one previous paper that considers how the relationship between the brand firm and generic firm may influence the likelihood of generic entry. Scott Morton (2002) considers the entry decisions of generic subsidiaries of brand companies. She finds that after controlling for the experience of the generic, generics owned by the original innovator (i.e., the brand company) are less likely to enter the market. The interpretation of this result is that once the generic has taken efficiencies related its own previous experience in the drug form, therapy and ingredients into account, the generic avoids competing with the brand-name drug in the same corporation. Further results are that generic entrants that belong to the corporation that owns the brand in the market are not more likely to deter other generics from entering.

\subsection{Common ownership}

Beginning with Rubinstein and Yaari (1983) and Rotemberg (1984), a number of authors have remarked that shareholder diversification can lead to firms internalizing the externalities they impose on rivals; see Schmalz (2018) for a full overview. These models show then that common ownership of competitors reduces incentives to compete as the gains of aggressive competition to one firm come at the expense of other firms in the investors' portfolio. Consequently, common ownership is predicted to lead to higher prices and boost industry profits. On the other hand, Lopez and Vives (2017) find that cost-reducing $R \& D$ investment with spillovers in a Cournot oligopoly may lead to higher welfare when there is higher common ownership.

Previous empirical studies on common ownership have mainly focused on the price effects of common ownership. In an empirical study focusing on the US airline industry, Azar et al. (2018) develop a modified Herfindahl-Hirschman index (MHHI) that provides a measure of the extent of common ownership at a market level. They find that ticket prices are about $3-12 \%$ higher on the average airline route than would be the case under separate ownership. Azar et al. (2016) focus on the US banking industry, extending the MHHI to take into account cross ownership (the extent to which banks own shares in each other), they find that common and cross ownership is correlated with banking fees. Further studies that look at the effect of common ownership on prices in airlines (Kennedy et al, 2017) and banking (Gramlich \& Grundl, 2017) using different methodologies find mixed and economically small effects. 
There are also some recent studies that highlight the positive effects that common ownership can have on market outcomes. Geng et al. (2017) find that vertical commonownership links can mitigate hold-up roblems arising from patent complementarities, which in turn is correlated with more innovation. Antón et al. (2017) examine how common ownership affects R\&D investments and innovation output. Cici et al. (2015) and Freeman (2016) find that common ownership between vertically connected firms can help strengthen business relationships. Ojeda (2017) documents that when a firm and a bank have common ownership, the firm receives larger loans from the bank at a lower interest rate.

\section{Theoretical framework}

We now present a simple framework to understand the effects of common ownership between an incumbent and potential entrants. We model, in particular, the decisions of the "generic firms" that have the possibility to manufacture and sell a generic drug and thus enter a market currently dominated by a "brand firm" that manufactures and sells the branded drug. This section focuses on the case of a single potential entrant but we analyze the case of multiple entrants in Section 7. We also propose several measures of common ownership based on prior literature.

\subsection{Basic model}

We make the following standard assumptions. Entry increases the market profits of the generic firm $G$, from zero to $\pi_{G}>0$, but reduces the profits of the brand firm $B$, from $\pi_{B}^{M}$ (monopoly) to $\pi_{B}^{D}$ (duopoly) with $\Delta \pi_{B} \equiv \pi_{B}^{D}-\pi_{B}^{M}<0$. We posit that the gains obtained by the generic firm are lower than the losses incurred by the brand firm, as competition reduces brand firm prices and profits enormously. As a result, although generic firm profits increase, $\pi_{G}>0$, joint profits decrease with entry, $\pi_{G}+\Delta \pi_{B}<0$.

Common ownership between the generic and the brand firm makes the entry decision non-trivial. Indeed, shareholders of the generic firm that also own shares in the brand firm may care, not only about the (increase in) profits of the generic firm, but also about the reduction of joint profits. A key issue, discussed below, is how common ownership affects decision-making. For the moment, let us denote by $\delta$ the weight that decision-makers of the generic firm place on joint (rather than on individual) profits as a result of common ownership. As a result of this, entry will only occur if the net gains are positive, i.e., as long as 


$$
(1-\delta) \pi_{G}+\delta\left(\pi_{G}+\Delta \pi_{B}\right)>0
$$

In the absence of common ownership, decision makers should place no weight on joint profits $(\delta=0)$ and entry is profitable (as $\left.\pi_{G}>0\right) .{ }^{6}$ At the other extreme, in the case common ownership is so high that joint profits are equally important than individual generic firm profits $(\delta=1)$, entry is not profitable (as $\pi_{G}+\Delta \pi_{B}<0$ ). Entry is reduced by an increase in the level of common ownership between the two firms (as $\left.\Delta \pi_{B}<0\right)$. Notice that an alternative interpretation of the weight on joint rather than on individual profits is equivalent to the importance of the change in profits of the brand drug firm relative to the profits of the generic firm profits, as (1) can be rewritten as

$$
\pi_{G}+\delta \Delta \pi_{B}>0
$$

Summarising the key result of this subsection:

Proposition 1. Higher levels of common ownership between the generic and the brand firm lowers the incentives to enter of the generic firm.

\subsection{Measures of common ownership}

Following previous literature, we now propose several measures to parametrize the impact of common ownership levels on $\delta$. We thus propose several ways in which investor holdings can affect decision-making. Our empirical results are robust to multiple measures of common ownership. ${ }^{7}$

Production function approach This approach assumes that there exists a "production function" that transforms each investor's shareholdings in the two firms (two inputs) onto the weight that the investor places on joint rather than on individual profits (output), and that these weights add up to the weight placed by the decision-makers. In formal terms, there exists a function $f$ such that

$$
\delta=\sum_{j} f\left(\gamma_{j G}, \gamma_{j B}\right)
$$

\footnotetext{
${ }^{6}$ Note that $\pi_{G}$ may include "other" costs of entry, and thus $\pi_{G}$ is the net gain which we assume is positive.

${ }^{7}$ Beyond our three main measures, we considered other measures of common ownership, including the "maximum ownership stake" $\delta_{M}$ (Gilje et al.,2018), the "geometric average ownership stake" $\delta_{G}$ (Gilje et al.,2018), and a variant of the measure used by Harford et al. (2011), $\delta_{H}$. A description of these additional measures and results using these measures can be found in an Appendix.
} 
where $\gamma_{j G}$ and $\gamma_{j B}$ are the shareholdings of a "common" shareholder $j$ that owns shares in the two firms. Naturally, the marginal effect of each of the two arguments of $f$ should be positive (non-negative) but there should be some degree of complementarity between the two. In other words, the marginal effect of the shareholding in one firm is larger if the shareholding in the other is higher. As two extreme (production function) examples (Gilje et al., 2018), the two shareholdings can be perfect substitutes (no complementarities), i.e.,

$$
f\left(\gamma_{j G}, \gamma_{j B}\right)=\left(\gamma_{j G}+\gamma_{j B}\right) / 2
$$

or perfect complements, i.e.,

$$
f\left(\gamma_{j G}, \gamma_{j B}\right)=\min \left\{\gamma_{j G}, \gamma_{j B}\right\}
$$

In both examples, the decision-makers shall place no weight on joint profits $(\delta=0)$ if there are no common shareholders, and they place full-weight on joint profits $(\delta=1)$ if all shareholders own the same fractions of shares in the two firms. But, example (3) does not penalize unequal shareholdings in the two firms whereas example (4) does. For instance, a shareholder that owns $5 \%$ of the shares of one firm and $15 \%$ of the other would have the same contribution to $\delta$ as someone that owns $10 \%$ in both firms in (3) but only half of it in (4). ${ }^{8}$ While (3) will most likely overstate the effect of common shareholders, (4) will most likely understate it.

Another way of interpreting (3) is that it represents the fraction of ownership at the pair level that is held in the hands of common investors. Hence it provides an indication of the relative importance of common vs. non-common investors for the firm pair.

For both measures, by aggregating shareholdings across common investors, we are also implicitly assuming that they can coordinate their collective decision making. This is a reasonable assumption if common owners have similar interests. Research by Fichtner et al. (2016) on the voting behaviour of BlackRock, Vanguard and State Street indicates that these three large common investors tend to vote similarly in almost all instances (more than 99\% of votes for each of them). A case study of a shareholder vote at the company DuPont also indicates how common investors can group together and use the power of their large voting block to implement their objectives (Schmalz, 2015).

\footnotetext{
${ }^{8}$ Note that for the first case, it is crucial the definition of what is a common shareholder. A shareholder with $100 \%$ and $0 \%$ would not count as a common shareholder, but someone with $100 \%$ and $0.1 \%$ would give a coefficient of 49.05 . That does not occur in the other two definitions
} 
Weighted sum of interests approach This approach, following O'Brien and Salop (2000), assumes that the decision-makers of the generic firm maximize a weighted sum of the interests of the investors in the firm, where (i) the interests of an investor are given by her shareholdings in the two firms and (ii) the weights are given by the investor's degree of control of the firm. As a result, common ownership will affect decision-making because common owners have financial interests in both firms and exert some degree of control on the generic firm decision-making. The interests of any (common or noncommon) shareholder $i$ who has holdings $\gamma_{i G}$ and $\gamma_{i B}$ are given by $\gamma_{i G} \pi_{G}+\gamma_{i B} \pi_{B}$. Assuming that control is proportional to ownership (the so-called proportional control model), the degree of control of the generic firm is given by $\gamma_{i G}$. Decision-makers of the generic firm should maximize

$$
\sum_{i} \gamma_{i G}\left[\gamma_{i G} \pi_{G}+\gamma_{i B} \pi_{B}\right]
$$

where $\gamma_{i G}$ and $\gamma_{i B}$ are the shareholdings of any shareholder $i$ that owns shares in either (or both) of the two firms. Straightforward algebra shows that maximizing this is equivalent to maximizing

$$
\pi_{G}+\frac{\sum_{i} \gamma_{i G} \gamma_{i B}}{\sum_{i} \gamma_{i G}^{2}} \pi_{B}
$$

and thus

$$
\delta=\frac{\sum_{i} \gamma_{i G} \gamma_{i B}}{\sum_{i} \gamma_{i G}^{2}}
$$

can be thought of a measure of "common ownership", as shown in (2). This measure captures the importance of control in the generic firm and ownership in the brand firm relative to control and ownership in the generic firm. See O'Brien and Waehrer (2017) for a thorough discussion of this measure often called "lambda".

\section{Data}

\subsection{The pharma industry}

Broadly speaking, pharmaceutical firms can be categorised as brand firms or generic firms. Brand firms undertake costly research and development to discover new medications and bring them to market, and must apply for FDA approval through the new drug application (NDA) procedure. Once a brand has received FDA approval, it is awarded "data exclusivity" for a period of three, five or seven years. ${ }^{9}$ Data exclusivity

\footnotetext{
${ }^{9}$ The duration of the exclusivity period differs in the type of drug: orphan drugs receive 7 years; generating antibiotics are eligible for 5 additional years; new chemical entities receive 5 years; new
} 
protects the underlying clinical data and runs concurrently with patent protection The period that spans between the end of data exclusivity and the expiration of the last patent is commonly referred to as "market exclusivity."

Generic firms produce biologically identical replications of brand drugs at a much lower cost, after they have already been marketed as brand-name products. Generic firms are able to enter a particular drug market once the regulatory protections afforded to the brand product have expired. During the market exclusivity period, generic companies can challenge the monopoly rights of the brand in court for instance through "paragraph IV" certification. ${ }^{10}$ Generic companies can also apply for FDA approval once all patents are expired. In both instances, an abbreviated new drug application (ANDA) must be submitted to the FDA. ${ }^{11}$ The protection conferred to new drugs is illustrated in Figure 1.

Figure 1: Exclusivities and Patent Protection in Pharmaceuticals

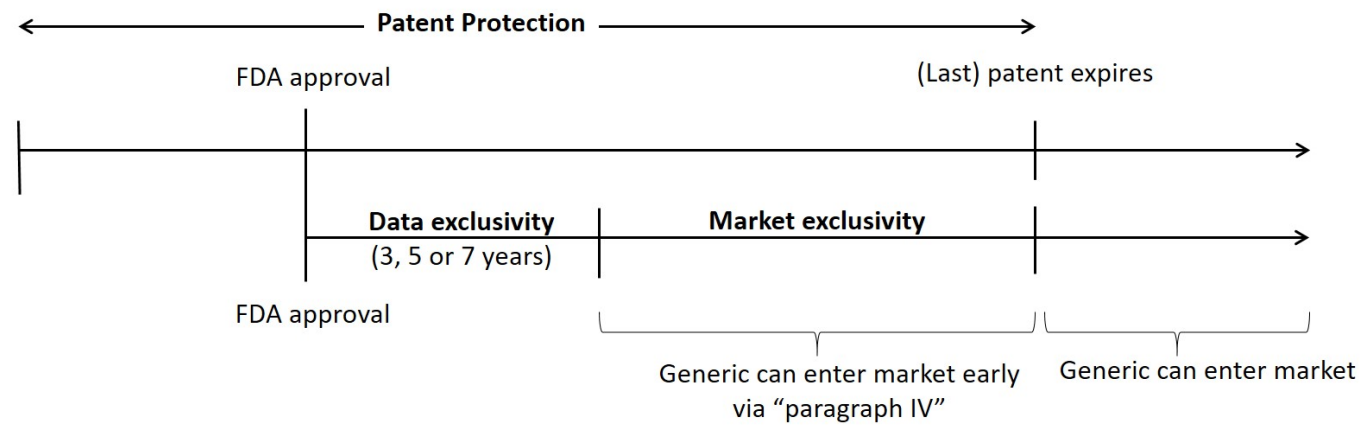

Notes: This figure illustrates the two types of protection awarded to new drugs. Data exclusivity protects the underlying clinical data and runs concurrently with patent protection. At the end of data exclusivity, a drug is protected only by its patents until they expire, a period termed "market exclusivity."

In line with Scott Morton (1999, 2000), we use FDA approval as an indicator of entry. We consider a drug product market to be open for generic entry at the earlier of either the date of first generic entry or the end of the market exclusivity period. We term this point in time the "end of exclusivity."

We focus on early entry and consider (simultaneous) entry that occurs within 18 months after the end of exclusivity. This is because the entire application process for generic drugs takes about 18 months on average, depending on the application's quality

clinical investigations receive 3 years; and the pediatric exclusivity adds 6 months of exclusivity.

${ }^{10} \mathrm{As}$ an incentive, if this certification is obtained, the generic is granted the exclusive right to market the generic drug for 180 days.

${ }^{11}$ A separate ANDA must be filed for each dosage form and strength. 
and unexpected FDA delays (Scott Morton, 2000). Information on ANDA's received by the FDA is kept secret until approval; in this sense entry decisions are simultaneous. ${ }^{12}$

We obtain NDA and ANDA information from the FDA Orange Book. The FDA Orange Book provides data on all launched pharmaceutical products in the United States since 1982. The data includes information on the launching company, type of drug (NDA or ANDA), patents associated, list of ingredients, dosage form, strength, approval date (which we convert into quarters) and status (prescription, over-the-counter, or discontinued). ${ }^{13}$ Information on the submission class of the brand product is merged in from the "Drugs at FDA" database using the FDA application number. ${ }^{14}$ Data concerning sales of brand drugs is taken from the website drugs.com. ${ }^{15}$ Additionally, products are linked to their relevant therapeutic field using the ATC/DDD Index 2015 and applying exact text matching based on compound-name. ${ }^{16}$

We define product markets at the ingredient-form level. ${ }^{17}$ In the FDA Orange Book, a drug product can in principle be identified as a unique ingredient-form-strength combination. In total, the Orange Book reports 3964 products at the ingredient-formstrength level that were launched from 1982 until 2017. We restricted the data in multiple ways, as is explained in detail in the Data Appendix. We consider only drug products that faced generic entry or patent expiry between 2004 and 2014, as this is the range for which we have data on all relevant variables. The final dataset contains 451 prescription drug product markets that faced generic entry and/or patent expiry between 2004 and 2014.

\footnotetext{
${ }^{12}$ Our results are robust to other entry period definitions such as entry within one or two years after the end of exclusivity.

${ }^{13}$ The Orange Book has been downloaded from the FDA website for each year $(2001 \mathrm{q} 4,2002 \mathrm{q} 4, \ldots$, 2017q4) using Internet Archive. In the current version of the Orange Book online the names of companies have been partially back-dated to display the current manufacturer of a drug. To establish the company name and drug status at the time of approval it was necessary to merge information from multiple versions of the FDA Orange Book.

${ }^{14}$ The main submission classes include Type 1 New Molecular Entity, Type 2 New Active Ingredient, Type 3 New Dosage Form, Type 4 New Combination, Type 5 New Formulation or Other Differences (e.g., new indication, new applicant, new manufacturer).

${ }^{15}$ Drugs.com provides the annual US sales figures for the top 200 drugs for the years 2003 -2010 and the top 100 drugs for the years 2011- 2013.

${ }^{16}$ The ATC/DDD Index 2015 categorizes all chemical compounds used in any therapeutic field according to a five-level hierarchical system, called the Anatomical Therapeutic Chemical (ATC) Classification System. The highest level (ATC-1) consist of 14 anatomical main groups (e.g. Alimentray Tract and Metabolism (A) or Cardiovascular System (C)). The next lower level (ATC-2) describes 88 therapeutic main groups (e.g. Drugs used in Diabetes (A10) or Diuretics (C03)). Lower levels make even finer distinctions between products. The lowest level (ATC-5) indicates 3709 chemical substances.

${ }^{17}$ For example the drug with the brand-name Zyrtec in syrup form with the ingredient Cetirizine Hydrochloride $5 \mathrm{mg} / 5 \mathrm{ml}$ will be in the same product market as Zyrtec in syrup form with the ingredient Cetirizine Hydrochloride 10mg/10ml. However, the product Zyrtec Allergy with the ingredient Cetirizine Hydrochloride 10mg in the form of a tablet is considered to be a different product market.
} 
We match the brand company that produces the brand product (NDA) with the full sample of potential generic entrants to form a drug product-brand-generic observation. The sample of potential generic entrants includes pharmaceutical companies that launched at least one generic product in our drug markets. Results are robust to different definitions of the entrant set. In an Appendix we provide results for the case where we restrict the set of potential entrants to only those with experience in the relevant drug form/route. Doing so means that we drop 61 actual entry observations. ${ }^{18}$ Hence we do not restrict the entrant set further in our main analysis.

\subsection{Common ownership}

We use the Thomson Reuters Global Ownership Database, which includes holdings by each shareholder in each publicly listed firm for every year-quarter. For US-listed firms Thomson Reuters collects ownership information from 13F, 13D and 13G filings. For companies outside the US, information is sourced from stock exchange filings, trade announcements, company websites, company annual reports and financial newspapers. For each firm for each quarter in the period 2003-2014, we extracted data on the shareholders that own at least $1 \%$ of the shares, and computed yearly ownership averages. Figure 2 gives an example of the top 5 investors for the brand-generic pair Johnson \& Johnson-Mylan in 2014. As shown, in this pair common shareholders account for the lion's share of the ownership of the top 5 investors.

\begin{tabular}{|c|c|c|c|}
\hline \multicolumn{2}{|c|}{$\begin{array}{c}\text { Brand } \\
\text { Johnson \& Johnson }\end{array}$} & \multicolumn{2}{|l|}{$\begin{array}{l}\text { Generic } \\
\text { Mylan }\end{array}$} \\
\hline BlackRock & $6 \%$ & Vanguard Group & $7 \%$ \\
\hline Vanguard Group & $6 \%$ & BlackRock & $7 \%$ \\
\hline State Street Global & $5 \%$ & Goldman Sachs Group & $5 \%$ \\
\hline Royal Bank of Canada & $2 \%$ & State Street Global & $4 \%$ \\
\hline Fidelity Investments & $2 \%$ & Wellington Mgmt. & $4 \%$ \\
\hline
\end{tabular}

Table 1: Top 5 Largest Investors (2014)

Our measures of common ownership aim to capture the weight that the decisionmakers of the generic firm $G$ place on the joint profits of the pair $G$ - $B$. The empirical

\footnotetext{
${ }^{18}$ This is $5 \%$ of all actual entry observations.
} 
counterparts of the three measures introduced in the theory section are as follows. Firstly we use the production function measure that assumes that the shareholdings of the common investors in the two firms are perfect substitutes:

$$
\delta_{S}=\frac{\sum_{j}\left(\gamma_{j B}+\gamma_{j G}\right)}{\sum_{i}\left(\gamma_{i B}+\gamma_{i G}\right)},
$$

where the numerator runs over the investors $j$ that $G$ and $B$ have in common and the denominator runs over all the investors in our database. As there are other investors (that own less than 1\%), the denominator may be different from 2 . We also use the production function measure that assumes that the shareholdings are perfect complements:

$$
\delta_{C}=\sum_{j} \min \left\{\gamma_{j B}, \gamma_{j G}\right\}
$$

Lastly, we use the measure that assumes that decision-makers of the generic firm maximise a weighted sum of the interests of the firm:

$$
\delta_{L}=\frac{\sum_{i} \gamma_{i B} \gamma_{i G}}{\sum_{i} \gamma_{i G}^{2}}
$$

For private firms, i.e. not listed on a stock-exchange, we assume that they do not have common investors with any other firm. For firms with a presence in the UK, we verified that this assumption holds true using annual return filings with full shareholder list also available for private firms from the company registry (Companies House).

Subsidiaries are assigned the ownership structure of their parent firm. Subsidiaries are identified on the basis of public information, including company websites, as well as on the basis of the Thomson Reuters database. We consider a firm X to be subsidiary of a firm Y if firm Y has more than $50 \%$ direct ownership stake of firm X. We can also identify cross-ownership links, i.e., when one firm has an ownership stake of less than $50 \%$ in another firm. However there are only three pairs in the dataset where the brand has a stake-holding in the potential generic entrant (Daiichi-Ranbaxy, Galderma-Alcon and Novartis-Alcon) and only one pair where the potential generic entrant has a stakeholding in the brand (Taro-Sun). As this ends up being too few observations to draw meaningful statistical conclusions, we do not consider these links in the analysis.

We pay particular attention to the case in which the potential generic entrant is a subsidiary of the brand firm. We create an indicator variable, named Subsidiary, that takes on the value 1 if the potential generic entrant is a subsidiary of the brand and 0 if it is not. In the former, the common ownership variables are set to zero. 
In the main specification we will report results using common ownership measured in the year prior to the end of exclusivity. Indeed, entry requires time to acquire an approved source of materials and suitable production facilities. About one to two years before filing an ANDA application, the generic firm starts preparing to enter (Reiffen and Ward, 2005). ${ }^{19}$

Figure 2 shows the evolution of the common ownership measures over time. We only include the company-pairs that are observed for the entire period, as this provides a robust overview of how the degree of connectedness between brand and generic pairs has changed over time. It is evident that on average common ownership has increased significantly from 2003 to 2014. The growth of common ownership was low, but still positive, until the beginning of 2010 and then, starting from 2011, the average level of common ownership almost doubled in the last years of the sample. ${ }^{20}$

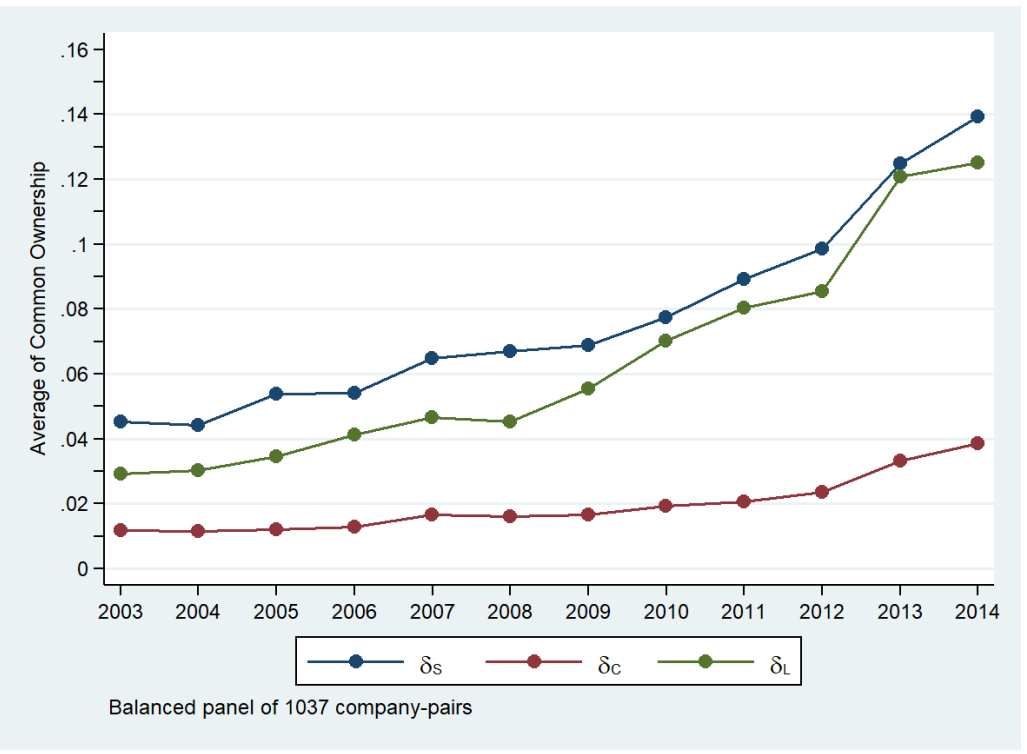

Figure 2: Evolution of common ownership

\subsection{Sample and variables}

Our final sample consists of 451 drug product markets and 58,737 drug product-brandgeneric observations. In total there are 102 unique brand companies (of which 77 are publicly listed at some time point) and 145 unique generic companies (of which 69 are

\footnotetext{
${ }^{19}$ Since it is unclear at exactly what point time the final entry decision of the generic firm is made, we also checked that our results are robust to the use of common ownership measured two and zero years prior to the end of exclusivity.

${ }^{20}$ This trend also holds when we restrict our attention to only those pairs where both brand and generic are publicly held companies.
} 
publicly listed at some time point). There are 13,954 unique pairs. Pairs may enter and exit the sample over time depending on whether companies in the pair enter (by incorporation) or exit the sample (by acquisition or bankruptcy). On average there are 131 potential generic entrants per market. This is comparable with previous studies: in Scott Morton (1999) there are 123 potential generic entrants per drug market and in data sample 1 in Appelt (2015) there are 100 potential entrants per drug market.

Table 2 gives an example of the structure of our data in terms of drug market, brand firm, potential generic entrants, entry and common ownership measures. The example relates to the drug Ultracet which is an analgesic produced by the company Janssen, which is a subsidiary of Johnson \& Johnson. The relevant market is defined by the ingredients (acetaminophen; tramadol hydrochloride) and dosage form (tablet; oral). The patent associated with Ultracet expired in 2011q3. Entry is defined within 18 months of the end of market exclusivity, in this case between 2011q3 and 2013q1. According to this definition the generics Barr and Amneal (as well as others not shown) have entered the market. The common ownership measures correspond to those of the year 2010 .

\begin{tabular}{|c|c|c|c|c|c|c|c|c|c|}
\hline obs. & trade name & ingredients & dosage form & brand & generic entrant & entry & $\delta_{S}$ & $\delta_{C}$ & $\delta_{L}$ \\
\hline 1 & ultracet & acetaminophen; tramadol hydrochl. & tablet; oral & JANSSEN & BAXTER & 0 & 0,62 & 0,21 & 0,65 \\
\hline 2 & ultracet & acetaminophen; tramadol hydrochl. & tablet; oral & JANSSEN & BARR & 1 & 0,53 & 0,15 & 0,41 \\
\hline 3 & ultracet & acetaminophen; tramadol hydrochl. & tablet; oral & JANSSEN & TARO & 0 & 0,26 & 0,07 & 0,12 \\
\hline 4 & ultracet & acetaminophen; tramadol hydrochl. & tablet; oral & JANSSEN & SANDOZ & 0 & 0,05 & 0,01 & 0,02 \\
\hline 5 & ultracet & acetaminophen; tramadol hydrochl. & tablet; oral & JANSSEN & AMNEAL & 1 & 0 & 0 & 0 \\
\hline 6 & ultracet & acetaminophen; tramadol hydrochl. & tablet; oral & JANSSEN & AKORN & 0 & 0 & 0 & 0 \\
\hline & & & & & . & . & . & . & \\
\hline . & . & & & & & . & & & . \\
\hline
\end{tabular}

Table 2: Data Structure

Following prior literature (Hurwitz and Caves, 1988; Scott Morton, 1999; Kyle, 2000; Hudson, 2000; Saha et al., 2006; Regan, 2008; Glowicka et al., 2009; Moreno-Torres et al., 2009: Appelt, 2015), we control for drug market and generic firm characteristics. The drug market characteristics include a set of indicator variables for the pre-marketentry sales of the brand product. Sales Rank (1-10) takes the value 1 if the brand drug ranks in the top 10 drugs in terms of US sales in the year before the end of exclusivity. Sales Rank (11-50) and Sales Rank (51-100) are defined in a similar manner. The indicator variable Authorised Generic takes on the value 1 if the brand firm has launched an authorised generic in that particular market. We also take into account the intensity of inter-molecular competition in the therapeutic field (Appelt, 2015; Regan, 2008). Substitutes on Patent (ATC2) provides a count of the number of on-patent substitutive 
active ingredients listed in the same therapeutic field at the ATC-2 level in the quarter prior to the end of exclusivity. ${ }^{21}$ Similarly Substitutes off Patent (ATC2) measures the number of off-patent substitutive active ingredients. Further market characteristics include the therapeutic field of the drug (at the ATC-2 level), submission type of the brand firm, ${ }^{22}$ drug form/route (defined as oral, injection, topical, ophthalmic or inhalation) and the year of the end of exclusivity.

Generic firm characteristics aim to capture the prior experience of the generic in the relevant market. Controlling for generic firm characteristics has shown to be crucial in previous studies (Scott Morton, 1999; Scott Morton, 2002; Kyle, 2006). Experience Route serves as a proxy for the potential entrant's experience in the brand drug form/route by counting the number of products with identical route of administration previously launched by the generic one quarter prior to the end of exclusivity. Similarly Experience $A T C 2$ serves as a proxy of the entrant's experience in the relevant therapeutic field at the ATC-2 level. Experience New Drug is constructed as a count of the entrant's previously launched new drugs. Generic entrants that are also active in producing new drugs may hold some patents that ease entry. Breadth (ATC2) accounts for the breadth of the generic entrant's portfolio by counting the number of distinct ATC-2 markets in which the generic has been active in one quarter prior to the end of exclusivity. The variables concerning generic firm experience and substitutes are calculated using the full FDA Orange Book. Counts start in 1994, 10 years before the start of the sample. ${ }^{23}$

Table 3 outlines the key characteristics for the 451 entry opportunities. The unconditional probability of entry is $2 \%$. Hence the vast majority of potential generic entrants do not enter. ${ }^{24} 111$ out of 451 markets (25\%) experience no entry within 18 months. In $26 \%$ of the markets the brand has launched a generic itself, i.e. an authorised generic. In terms of brand revenues, $2 \%$ of drug markets are ranked in the top 10 drugs in terms of sales in the year prior to the end of exclusivity, $7 \%$ are ranked in the top 11-50, and $7 \%$ are in the top 51-100 drugs. On average a potential generic entrant has launched 13 generic products of the same route/form as the brand and is active in 11 therapeutic

\footnotetext{
${ }^{21}$ Whereas the ATC-3 level is most in line with market definition in M\&A approval procedures in Europe and the United States, through the matching process one drug may be linked with numerous therapeutic classes at the ATC3 level. To ensure that we obtain a unique therapeutic for each drug, we use the broader market definition of ATC2.

${ }^{22}$ New dosage form, new molecular entity or new active ingredient, new formulation or other differences, or new combination.

${ }^{23}$ Results are robust to other starting points.

${ }^{24}$ This is similar to previous studies: in Scott Morton (1999) 2-7\% of entry opportunities are realised, in Kyle (2006) 2.5\% of entry opportunities are realised, and in Appelt (2015) 10\% of entry opportunities are realised.
} 
fields.

\begin{tabular}{lccccc}
\hline \hline Variable & Obs. & Mean & Std. Dev. & Min & Max \\
\hline Entry $(0 / 1)$ & 58737 & 0.02 & 0.14 & 0 & 1 \\
$\delta_{S}$ & 58737 & 0.074 & 0.15 & 0 & 0.868 \\
$\delta_{C}$ & 58737 & 0.021 & 0.051 & 0 & 0.366 \\
$\delta_{L}$ & 58737 & 0.062 & 0.16 & 0 & 1.365 \\
Subsidiary $(0 / 1)$ & 58737 & 0.002 & 0.045 & 0 & 1 \\
Sales Rank $(1-10)(0 / 1)$ & 58737 & 0.022 & 0.146 & 0 & 1 \\
Sales Rank (11-50) $(0 / 1)$ & 58737 & 0.069 & 0.253 & 0 & 1 \\
Sales Rank (51-100) (0/1) & 58737 & 0.067 & 0.251 & 0 & 1 \\
Authorised Generic $(0 / 1)$ & 58737 & 0.26 & 0.439 & 0 & 1 \\
Substitutes on Patent $($ ATC2) $\div 10$ & 58737 & 2.325 & 1.669 & 0 & 7.3 \\
Substitutes off Patent $($ ATC2) $\div 10$ & 58737 & 1.6 & 1.31 & 0 & 6.1 \\
Experience Route $\div 10$ & 58737 & 1.305 & 3.086 & 0 & 29.9 \\
Experience ATC2 $\div 10$ & 58737 & 0.07 & 0.223 & 0 & 3.2 \\
Experience New Drug $\div 10$ & 58737 & 0.179 & 0.424 & 0 & 2.8 \\
Breadth (ATC2) $\div 10$ & 58737 & 1.135 & 1.204 & 0 & 6.1 \\
\hline \hline
\end{tabular}

Table 3: Summary Statistics

\section{Empirical implementation}

We determine which generic firms are more likely to enter a given drug market. The binary dependent variable contains the market entry decision of the generic firm. The resulting equation to be estimated is:

$$
\operatorname{Pr}\left[\text { Entry }_{G m}=1\right]=\beta_{0}+\beta \delta_{G m}+\eta Z_{m}+\gamma X_{G m}+\alpha_{m}+\epsilon_{G m}
$$

Entry $y_{G m}$ takes on the value 1 when generic $G$ enters market $m$ (ingredient-form) within 18 months after the end of exclusivity (defined as the earlier of last patent expiry date and first generic entry). $\delta_{G m}$ is one of the measures of common ownership between the generic firm and the brand for the product market, where $\delta_{G m}$ can be $\delta_{S}, \delta_{C}$ or $\delta_{L}$. $Z_{m}$ is a vector of market characteristics, including market size as measured by pre-genericentry sales, an indicator for the presence of an authorised generic, the number of patent protected inter-molecular substitutes in the same therapeutic field and the number of off patent inter-molecular substitutes in same therapeutic field. $X_{G m}$ is a vector of genericmarket characteristics, including generic's previous experience with drug from/route, generic's previous experience with the therapeutic class defined at ATC-2 level, generic's previous experience with new drugs, number of therapeutic fields in which the generic 
has experience and region of generic's company headquarters (e.g. Southern Asia). ${ }^{25}$ Fixed effects $\alpha_{m}$ are included for drug dosage form, submission type, therapeutic field (ATC-2 code) and year of the end of exclusivity.

We first estimate a linear probability model (LPM). In our case a LPM model is able to estimate more parameters than a probit model. In the case of the probit model certain dummy variables perfectly predict the outcome hence these observations are dropped. ${ }^{26}$ Coefficients for the probit and logit models are also reported.

The coefficient $\beta$ measures the impact of common ownership between the brand and the generic on the generic's entry decision. If institutional investors adjust their holdings in response to entry opportunities (at the ingredient-form level), common ownership might be endogenous. For example if investors in the brand increase investment in generics with entry plans, common ownership between the brand and generic will increase before entry, causing $\beta$ to be biased upward.

To address endogeneity concerns, we also perform IV estimations and instrument for common ownership with financial index membership at the pair level. ${ }^{27}$ We use the holdings included in the iShares U.S. Pharmaceutical (IHE) ETF during the 2006-2014 period. The fund, launched in 2006 and managed by BlackRock, tracks the investment results of the Dow Jones U.S. Select Pharmaceutical Index, which in turn is designed to measure the performance of the pharmaceutical sector of the US equity market. The Dow Jones US Select Pharmaceutical Index includes a wide range of pharmaceutical companies including both brand and generic companies. According to BlackRock (2017), the IHE fund generally invests at least 90\% of its assets in securities or other financial instruments related to the Dow Jones U.S. Select Pharmaceutical Index.

On average, the fund has been comprised of 39 holdings over time, each allocated a specific weight that changes over time. ${ }^{28}$ Since May 2006 each company has been listed on the exchange-traded fund for an average of 4 years. This evidences the pattern of

\footnotetext{
${ }^{25}$ Regions are defined as Australasia, Eastern Asia, Eastern Europe, Northern America, Northern Europe, South-eastern Europe, Southern Asia, Southern Europe, Western Asia, Western Europe.

${ }^{26}$ As noted by Caudill (1988) if the model contains a dummy variable for membership in some group, and every member of the group has the same value for the dependent variable, the coefficient of the group dummy variable cannot be estimated in logit or probit models, but can be estimated in the linear probability model.

${ }^{27} \mathrm{~A}$ similar approach has been applied by several other papers in the literature. For example Aghion (2013) use the inclusion of a firm in the S\&P 500 as an instrument for institutional ownership. Bena et al. (2017) instrument foreign institutional ownership with stock additions and deletions to the MSCI All Country World Index. Schmidt and Fahlenbach (2017) instrument passive institutional ownership with switches between the Russel 1000 and Russel 2000 indexes. They argue that investors tracking the Russel 1000 index will significantly increase their holdings in firms that switch from the Russel 2000 to the Russel 1000 index.

${ }^{28}$ The relative weightings are computed using the market-cap methodology whereby the securities are valued according to their total market capitalization.
} 
entry and exit of the fund which has been marked by various periods of high entrance and exit (e.g., more than 6 companies dropped out and entered the fund in the last quarter of 2013 and the third quarter of 2015, respectively) and periods of no change.

We construct a set of instrumental variables. The instrument that we use in the main specification is the variable Index Periods. Index Periods is constructed by adding up the number of quarters that both firms have appeared in the index up until one year prior to the end of exclusivity. ${ }^{29}$ We expect that the longer both companies are present in the IHE index, the more investment in both companies will increase by investors that track the Dow Jones U.S. Select Pharmaceutical Index, leading to higher common ownership levels. The identifying assumption is that inclusion in the exchange-traded fund, which mirrors the pharmaceutical index, is exogenous to market entry, except through its effect on common ownership. This is the case provided that the index is not created with potential entry opportunities in mind (at the ingredient-form level) and that, controlling for other factors, addition to the index does not directly affect entry decisions except through common ownership.

We further construct an additional instrument based on the pharmaceutical company headquarters. The instrument Same Region takes on the value 1 when both companies in the pair have headquarters located in the same geographic region and 0 when the regions differ. ${ }^{30}$ We expect that companies with headquarters in the same region will have higher common ownership due to regionally focused investors (see Appendix). That is, if both companies are located in Southern Asia the pair is likely to have higher common ownership than if one company was located in Southern Asia and the other in Northern America. The identifying assumption is that whether or not the brand and generic headquarters are in the same region does not directly affect the entry decision.

\section{$6 \quad$ Results}

Table 4 presents the main results for the OLS and IV estimations with our three common ownership measures. First off, the control variables carry the expected signs; higher preentry brand sales, fewer on-patent molecular substitutes and greater entrant experience

\footnotetext{
${ }^{29}$ Further instrumental variables that were constructed include; Index Presence which is an indicator variable that is 1 if one or both companies are included in the exchange-traded fund, Index Companies which counts the number of companies that are present in the fund and thereby can take on the values 0, 1 or 2 and Index Weights which sums the weights of each pair of companies and indicates their relative financial importance for every period.

${ }^{30}$ The regions in sample are defined as Australasia, Eastern Asia, Eastern Europe, Northern America, Northern Europe, South-eastern Europe, Southern Asia, Southern Europe, West Asia and Western Europe.
} 
all significantly increase the likelihood of entry. We find that the launch of an authorised generic and the number of molecular substitutes off-patent do not have a significant impact on generic entry. These results are similar to Appelt (2015) who finds that on-patent substitutes have a negative and significant effect, off-patent substitutes do not have a significant effect, and authorised generics do not have a significant effect on generic entry.

More importantly for this study, the coefficient on $\delta$ across all measures is negative and significant. Thus we find that common ownership between the brand and generic indeed reduces the likelihood of generic entry. ${ }^{31}$ The coefficient on common ownership should be interpreted bearing in mind the unconditional probability of entry for the sample. ${ }^{32}$ The unconditional probability of entry for the sample of firms and markets is $2 \%$. Focusing on the OLS estimations, an increase of one standard deviation as measured by $\delta_{S}$ implies a $0.15 \times 0.012=0.0018$ percentage point decrease in the probability of entry, ceteris parabis. This is therefore a $0.0018 / 0.02=9 \%$ reduction in the unconditional probability of entry. Similarly, an increase of one standard deviation in $\delta_{C}$ and $\delta_{L}$ imply an $11 \%$ and $13 \%$ decrease, respectively, in the probability of entry.

For the IV estimations, the first-stage results indicate that both instruments are highly relevant and positively correlated with $\delta$. However we cannot reject the hypothesis that $\delta$ is exogenous for all measures of $\delta$ (see Appendix). The IV results suggest an even more negative effect of common ownership on entry.

The effect of common ownership is smaller than the effect of being a subsidiary of the brand. For example, if $\delta_{S}$ is 1 , that is the brand and generic share all the same common owners, then the probability of entry falls by 1.2 percentage points, whereas if the relationship is parent-subsidiary the probability of entry falls by 4 percentage points. This finding suggests that while in theory complete common ownership by multiple shareholders could be identical to full ownership, our results suggest that in reality, this may not be the case.

The size of the coefficient on $\delta_{S}$ can also be compared to the effect of an increase in market experience. The impact of having launched an additional 10 products of the same route/form as the brand product prior to entry, is to increase the probability of entry by 0.8 percentage points.

\footnotetext{
${ }^{31}$ This result is robust to different specifications including logit and probit specifications, different entrant sets, measuring common ownership at different time points and additional measures of common ownership (see Appendix).

${ }^{32}$ Like Scott Morton (2002), we find that controlling for generic experience is crucial. The addition of generic market experience variables changes the sign on $\delta$ from positive to negative (see Appendix). Hence, only once generic experience has been taken into consideration, does common ownership reduce the likelihood of generic entry.
} 
In Table 5 we present results where common ownership is specified as a categorical variable. We specify common ownership as a categorical variable in order to investigate whether greater levels of common ownership have a larger impact; i.e., whether the relationship between common ownership and entry is not linear. We focus on the measure $\delta_{S}$. This measure can be interpreted as the fraction of total ownership in the pair held by common investors, and hence presents natural thresholds. We construct 3 categorical variables based on the value of $\delta_{S}: \delta_{S}(0<\delta \leq 0.3)$ takes on the value 1 if $\left.\left.\delta_{S} \in\right] 0 ; 0.3\right], \delta_{S}(0.3<\delta \leq 0.5)$ takes on the value 1 if $\left.\left.\delta_{S} \in\right] 0.3 ; 0.5\right]$, and $\delta_{S}(0.5<\delta \leq 1)$ takes on the value 1 if $\left.\left.\delta_{S} \in\right] 0.5 ; 1\right]$.

The results in Table 5 indicate that the effect of common ownership increases the greater the level of common ownership. The coefficients on each categorical variable increase in magnitude (become more negative) with higher common ownership. Only once $\delta_{S}$ is greater than 0.5 does the negative effect of common ownership on entry probability become significant. This result is robust across IV, probit and logit specifications (see Appendix for the latter two specifications). A change from zero common ownership to common ownership of greater than 0.5 reduces the entry probability of a generic by 0.9 percentage points on average. This is a $50 \%$ decline in the unconditional probability of entry. In our sample we find that there are 669 unique brand-generic pairs with a $\delta_{S}$ of greater than 0.5 at some point is time. This is $5 \%$ of all brand-generic pairs. 


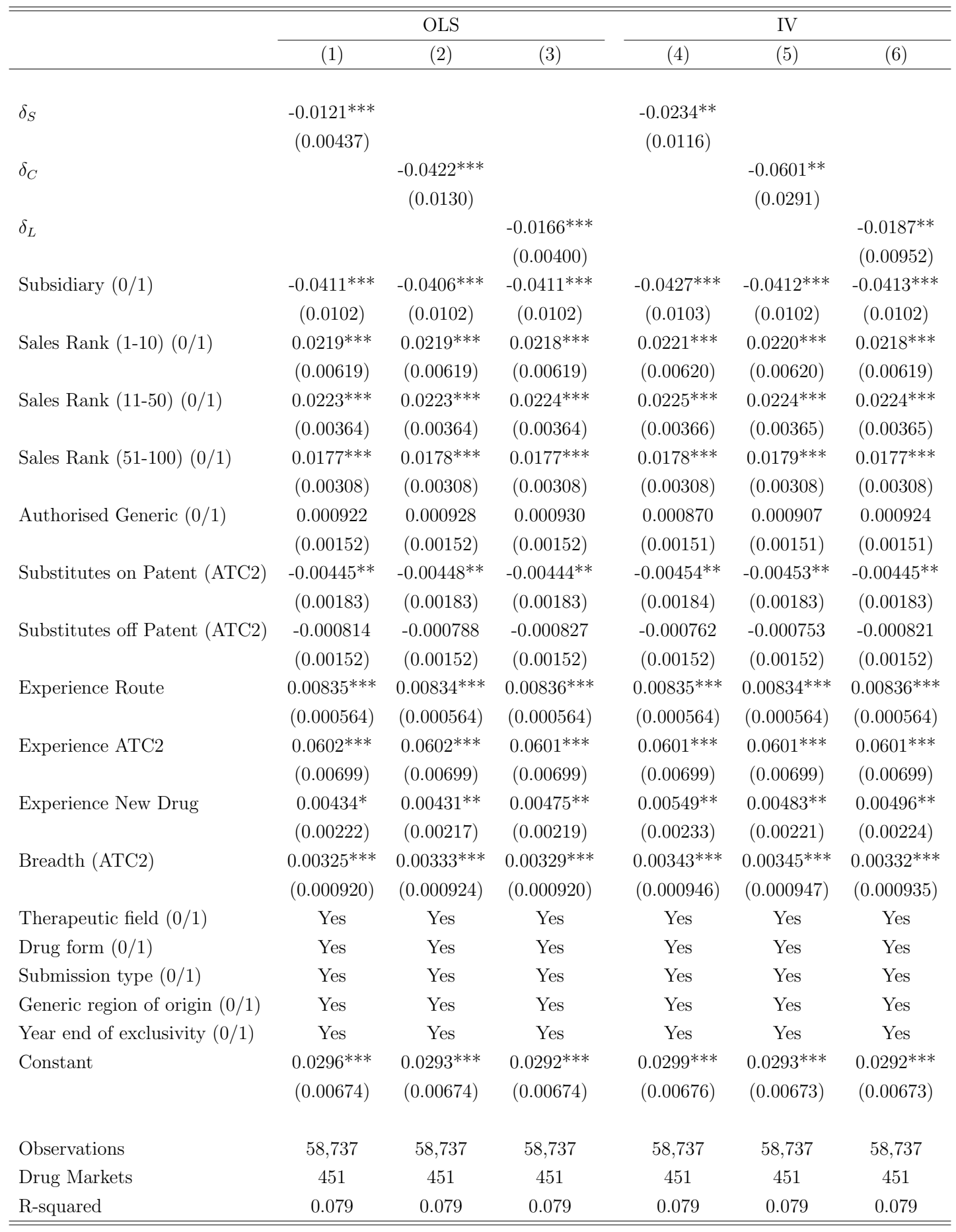

Notes: Standard errors in parentheses are robust. The dependent variable is entry within 18 months. The instruments are the number of periods listed in the ETF iShares U.S. Pharmaceutical (IHE) and an indicator variable that takes on the value 1 when the main headquarters of both companies are located in the same region. $* * * p<0.01, * * p<0.05, * p<0.1$.

\section{Table 4: Main Specification}




\begin{tabular}{|c|c|c|}
\hline & OLS & IV \\
\hline \multirow[t]{2}{*}{$\delta_{S}(0<\delta \leq 0.3)$} & $0.00320^{*}$ & -0.00420 \\
\hline & $(0.00180)$ & $(0.00311)$ \\
\hline \multirow[t]{2}{*}{$\delta_{S}(0.3<\delta \leq 0.5)$} & -0.00322 & -0.00581 \\
\hline & $(0.00288)$ & $(0.00387)$ \\
\hline \multirow[t]{2}{*}{$\delta_{S}(\delta>0.5)$} & $-0.00919^{* * *}$ & $-0.0109^{* *}$ \\
\hline & $(0.00335)$ & $(0.00438)$ \\
\hline \multirow[t]{2}{*}{ Subsidiary $(0 / 1)$} & $-0.0394^{* * *}$ & $-0.0422^{* * *}$ \\
\hline & $(0.0102)$ & $(0.0103)$ \\
\hline \multirow[t]{2}{*}{ Sales Rank (1-10) (0/1) } & $0.0218^{* * *}$ & $0.0219^{* * *}$ \\
\hline & $(0.00619)$ & $(0.00619)$ \\
\hline \multirow[t]{2}{*}{ Sales Rank (11-50) (0/1) } & $0.0224^{* * *}$ & $0.0223^{* * *}$ \\
\hline & $(0.00364)$ & $(0.00364)$ \\
\hline \multirow[t]{2}{*}{ Sales Rank (51-100) (0/1) } & $0.0176^{* * *}$ & $0.0178^{* * *}$ \\
\hline & $(0.00308)$ & $(0.00308)$ \\
\hline \multirow[t]{2}{*}{ Authorized Generic (0/1) } & 0.00104 & 0.000904 \\
\hline & $(0.00151)$ & $(0.00151)$ \\
\hline \multirow[t]{2}{*}{ Substitutes on Patent (ATC2) } & $-0.00434^{* *}$ & $-0.00452^{* *}$ \\
\hline & $(0.00183)$ & $(0.00183)$ \\
\hline \multirow[t]{2}{*}{ Substitutes off Patent (ATC2) } & -0.000906 & -0.000802 \\
\hline & $(0.00152)$ & $(0.00151)$ \\
\hline \multirow[t]{2}{*}{ Experience Route } & $0.00838^{* * *}$ & $0.00834^{* * *}$ \\
\hline & $(0.000564)$ & $(0.000564)$ \\
\hline \multirow[t]{2}{*}{ Experience ATC2 } & $0.0603^{* * *}$ & $0.0602^{* * *}$ \\
\hline & $(0.00698)$ & $(0.00699)$ \\
\hline \multirow[t]{2}{*}{ Experience New Drug } & 0.00365 & $0.00496^{* *}$ \\
\hline & $(0.00224)$ & $(0.00227)$ \\
\hline \multirow[t]{2}{*}{ Breadth (ATC2) } & $0.00292^{* * *}$ & $0.00342^{* * *}$ \\
\hline & $(0.000928)$ & $(0.000955)$ \\
\hline Therapeutic field $(0 / 1)$ & Yes & Yes \\
\hline Drug form $(0 / 1)$ & Yes & Yes \\
\hline Submission type $(0 / 1)$ & Yes & Yes \\
\hline Generic region of origin $(0 / 1)$ & Yes & Yes \\
\hline Year end of exclusivity $(0 / 1)$ & Yes & Yes \\
\hline \multirow[t]{2}{*}{ Constant } & $0.0280^{* * *}$ & $0.0308^{* * *}$ \\
\hline & $(0.00679)$ & $(0.00689)$ \\
\hline Observations & 58,737 & 58,737 \\
\hline Drug markets & 451 & 451 \\
\hline R-squared & 0.079 & 0.079 \\
\hline
\end{tabular}

Notes: Standard errors in parentheses are robust. The dependent variable is entry within 18 months. The instruments are the number of periods listed in the ETF iShares U.S. Pharmaceutical (IHE) and an indicator variable that takes on the value 1 when the main headquarters of both companies are located in the same region. $* * * p<0.01, * * p<0.05, * p<0.1$.

Table 5: Categorical Variables Specification 


\section{Multiple entrants}

We now extend the basic framework to take into account that several generic firms may be deciding whether to enter the market of the brand firm. We first show in a theoretical framework with two generic potential entrants that the classical result of entry decisions being strategic substitutes may be reversed in the presence of common ownership. Indeed, for high levels of common ownership entry decisions become strategic complements.

We then show that the results of the basic model on the effects of common ownership on entry of the focal generic firm extend to the case of multiple generics: an increase in the level of common ownership between the focal generic firm and brand firm reduces the likelihood of entry of the generic. We thereafter show that the likelihood of entry of the focal generic firm is increased (reduced) by the degree of common ownership of the other generic if and only if entry decisions are characterised by strategic substitutability (complementarity). Further, although the overall effect of the other generic's degree of common ownership on the likelihood of entry by the focal generic may be ambiguous, it is more likely to be negative and decrease the likelihood of entry of a generic firm if its own degree of common ownership is large, i.e. the interaction effect is negative.

We test these predictions in an empirical setup where we select as other potential generic entrant the most experienced generic competitor. In this setup, we find confirmation that our main result still holds: an increase in the level of common ownership between the focal generic firm and brand firm reduces the likelihood of entry of this generic. Further, we find some evidence that, on average, entry decisions are characterised by strategic substitutability. Moreover, interaction effects are indeed negative. Finally, in a thought exercise where we assume that common ownership between the brand and both generic potential entrants is symmetric, we find that, again in line with

our theoretical framework, for common ownership above 0.45 entry decisions become strategic complements.

\section{1 $\quad$ Model}

Two symmetric (risk-neutral) generic firms, $G$ and $G^{\prime}$, can enter the market of the product of the brand firm $B$. As before, denote the weight placed by the decisionmakers of the generic firms $G$ and $G^{\prime}$ on joint profits with brand firm $B$ (rather than on individual generic firm) profits by $\delta$ and $\delta^{\prime}$, respectively. Denote the profits of the generic firms $k=G, G^{\prime}$ in a market structure $m=D$ or $T$, denoting duopoly and triopoly, as $\pi_{k}^{m}$ and the change in profits of the brand firm $B$ from monopoly to duopoly and from 
duopoly to triopoly as $\Delta \pi_{B}^{D} \equiv \pi_{B}^{D}-\pi_{B}^{M}$ and $\Delta \pi_{B}^{T} \equiv \pi_{B}^{T}-\pi_{B}^{D}$, respectively. We assume, as before, that $\Delta \pi_{B}^{D}<0$ and $\Delta \pi_{B}^{T}<0$ but, as the reduction of profits decrease with the number of entrants, $\Delta \pi_{B}^{D}<\Delta \pi_{B}^{T}$. We also assume away collusion.

Extending the reasoning of the basic model, and denoting the probability that the competitor of firm $G$ (i.e. $G^{\prime}$ ) enters as $p$, generic firm $G$ should enter the market as long as the net gains of entry (or the "incentives" to enter) $\Pi_{G}>0$, where

$$
\Pi_{G}(p, \delta) \equiv(1-p) \pi_{G}^{D}+p \pi_{G}^{T}+\delta\left[(1-p) \Delta \pi_{B}^{D}+p \Delta \pi_{B}^{T}\right] .
$$

Notice that in the case in which the probability of $G^{\prime}$ entering is zero, $p=0$, this condition reduces to $\pi_{G}^{D}+\delta \Delta \pi_{B}^{D}>0$, as in equation (2) in our basic model. Here, the probability that the generic firm $G$ enters, which we shall denote by $p^{\prime}$ (as it is the competitor of firm $G^{\prime}$ ), may depend on $p$ and $\delta$. Similarly, $p$ depends on $p^{\prime}$ and $\delta^{\prime}$. Indeed, the generic firm $G^{\prime}$ will enter as long as $\Pi_{G^{\prime}}>0$, where

$$
\Pi_{G^{\prime}}\left(p^{\prime}, \delta^{\prime}\right) \equiv\left(1-p^{\prime}\right) \pi_{G^{\prime}}^{D}+p^{\prime} \pi_{G^{\prime}}^{T}+\delta^{\prime}\left[\left(1-p^{\prime}\right) \Delta \pi_{B}^{D}+p^{\prime} \Delta \pi_{B}^{T}\right] .
$$

\subsection{Entry decisions: strategic complements or substitutes?}

We now show that entry decisions are not necessarily strategic substitutes in the presence of common ownership.

To understand how the incentives to enter of generic firm $G$ change as the generic firm $G^{\prime}$ is more likely to enter, we derive $\Pi_{G}$ in (9) with respect to $p$ :

$$
\partial \Pi_{G}(p, \delta) / \partial p=-\left(\pi_{G}^{D}-\pi_{G}^{T}\right)+\delta\left(\Delta \pi_{B}^{T}-\Delta \pi_{B}^{D}\right) .
$$

We can identify two effects. The first term is negative and as result, firm $G$ has less incentives to enter if company $G^{\prime}$ is more likely to enter. This is the traditional (noncommon ownership) result of entry decisions being strategic substitutes. The second term is positive, and thus pulls in the other direction. As the other generic is more likely to enter, the effect on the brand company's profits is more likely to be from duopoly to triopoly rather than from monopoly to duopoly. This is of course less of a concern, given that the reduction in profits decreases with the number of entrants, i.e., $\Delta \pi_{B}^{T}>\Delta \pi_{B}^{D}$.

Because of the common ownership between the generic firm and the brand product company, the traditional result of strategic substitutabilities can be reversed. In particular, when $\partial \Pi_{G}(p, \delta) / \partial p>0$, then entry decisions are strategic complements. The 
trade-off can be understood as a balance between the (negative) first derivative with respect to the number of firms on the profits of the two-generic firms (first term) against the (positive) second derivatives on the profits of the branded product company (second term). In particular, for a high enough level of common ownership

$$
\delta>\delta^{*} \equiv-\left(\pi_{G}^{D}-\pi_{G}^{T}\right) /\left(\Delta \pi_{B}^{T}-\Delta \pi_{B}^{D}\right),
$$

$\partial \Pi_{G}(p, \delta) / \partial p>0$ and entry decisions are characterised by strategic complementarities. Summarising,

Proposition 2. For a high enough levels of common ownership, entry decisions are characterised by strategic complementarities.

\subsection{Comparative statics}

This section presents the comparative static predictions of the levels of common ownership of the two generic firms on the decision to enter of one of them, as well as the predicted interacted effects. We make use of the strategic interactions between the decisions of the two generics studied in the previous section to take into account the indirect effects.

Effects of common ownership of the focal generic firm We first show that the results of the basic model extend to the case of multiple generics. Namely, an increase in the level of common ownership decreases the incentive to enter of the focal generic firm.

Notice first that an increase in $\delta$ will negatively affect $\Pi_{G}$, as $\partial \Pi_{G} / \partial \delta=[(1-$ p) $\left.\Delta \pi_{B}^{D}+p \Delta \pi_{B}^{T}\right]<0$, but it will not affect $\Pi_{G^{\prime}}$ nor, thus, $p$ directly. In formal terms, by the chain rule,

$$
\partial \Pi_{G}(p, \delta) / \partial \delta=\underbrace{\partial \Pi_{G} / \partial p}_{\lessgtr 0} * \underbrace{\partial p / \partial \delta}_{=0}+\underbrace{\partial \Pi_{G} / \partial \delta}_{<0}<0 .
$$

Second, the equilibrium effects reinforce the direct effect, although the channel depends on whether entry decisions are strategic complements or substitutes. In the case where they are strategic substitutes, a decrease in the incentives to enter of $G$, i.e. a reduction of $p^{\prime}$, implies an increase in $\Pi_{G^{\prime}}$ and thus of $p$, which will reduce $\Pi_{G}$ and thus $p^{\prime}$ further. Repeating the process, we get less entry of firm $G$. Similarly, in case where they are strategic complements, a decrease in the incentives to enter of $G$, i.e. a reduction of 
$p^{\prime}$, implies a reduction in $\Pi_{G^{\prime}}$ and thus of $p$, which reduces $\Pi_{G}$ and thus $p^{\prime}$ further. Repeating the process, we again get less entry of firm $G$. Summarising,

Proposition 3. Higher levels of common ownership between the focal generic firm and the brand firm lower the incentives to enter of this generic firm.

Effects of common ownership of the other generic firm We now show that an increase in the level of common ownership of the other firm with the brand firm increases (decreases) the incentive to enter of a given generic firm if and only if entry decisions are strategic substitutes (strategic complements).

Suppose first that entry decisions are strategic substitutes. An increase in $\delta^{\prime}$ does not affect $\Pi_{G}$ directly, $\partial \Pi_{G} / \partial \delta^{\prime}=0$, but it reduces $\Pi_{G^{\prime}}$ and thus $p$, which in turn increases $\Pi_{G}$. In formal terms,

$$
\partial \Pi_{G}(p, \delta) / \partial \delta^{\prime}=\underbrace{\partial \Pi_{G} / \partial p}_{<0} * \underbrace{\partial p / \partial \delta^{\prime}}_{<0}+\underbrace{\partial \Pi_{G} / \partial \delta^{\prime}}_{=0}>0
$$

In terms of equilibrium effects, an increase in $\Pi_{G}$ and thus in $p^{\prime}$ implies that $p$ is reduced further, which in turn increases $\Pi_{G}$ and $p^{\prime}$ further. Repeating the process, we have more entry of firm $G$.

Suppose, second, that entry decisions are strategic complements. As before, an increase in $\delta^{\prime}$ does not affect $\Pi_{G}$ directly but it reduces $\Pi_{G^{\prime}}$ and thus $p$ :

$$
\partial \Pi_{G}(p, \delta) / \partial \delta^{\prime}=\underbrace{\partial \Pi_{G} / \partial p}_{>0} * \underbrace{\partial p / \partial \delta^{\prime}}_{<0}+\underbrace{\partial \Pi_{G} / \partial \delta^{\prime}}_{=0}<0
$$

In terms of equilibrium effects, a decrease in $\Pi_{G}$ and in thus $p^{\prime}$ implies that $p$ is reduced further, which in turn decreases $\Pi_{G}$ and $p^{\prime}$ further. Repeating the process, we have less entry of firm $G$. Summarising,

Proposition 4. Higher levels of common ownership between the other generic firm and the brand firm lower (increases) the incentives to enter of the focal generic firm if and only if entry decisions are strategic substitutes (strategic complements).

Interaction effects We now investigate how the effect of common ownership of a given firm on entry depends on the level of common ownership of the other firm. We show, on the one hand, that the effect of $\delta$ on entry is more negative as $\delta^{\prime}$ changes. Similarly, the effect of $\delta^{\prime}$ is relatively more negative as $\delta$ increases. In absolute terms, 
the effect of $\delta^{\prime}$ is positive for low levels of $\delta$ (e.g. when $\delta=0$ ) and negative for high levels of $\delta$.

To understand how the effects of $\delta$ on the probability of entry of $G$ change as we increase $\delta^{\prime}$, we take the derivative of (13) with respect to $\delta^{\prime}$ :

$$
\partial^{2} \Pi_{G}(p, \delta) / \partial \delta \partial \delta^{\prime}=\underbrace{\partial^{2} \Pi_{G} / \partial p \partial \delta}_{>0} * \underbrace{\partial p / \partial \delta^{\prime}}_{<0}+\underbrace{\partial^{2} \Pi_{G} / \partial \delta \partial \delta^{\prime}}_{=0}<0 .
$$

The first term is positive because, deriving (12) with respect to $\delta$, we have that $\partial^{2} \Pi_{G} / \partial p \partial \delta=\Delta \pi_{B}^{T}-\Delta \pi_{B}^{D}>0$. Although the effect of $p$ on the incentives to enter of firm $G$ may be ambiguous, $\partial \Pi_{G} / \partial p \gtreqless 0$, it should be relatively more complementary as $\delta$ increases. As a result of this, the effect of $\delta^{\prime}$ on the probability of entry of $G$ is relatively more negative as we increase $\delta$. But the absolute effect may be positive or negative. Indeed, in the case in which $\delta=0$, then $\partial \Pi_{G} / \partial p<0$ and, using (14), $\partial \Pi_{G}(p, \delta) / \partial \delta^{\prime}>0$. Summarising,

Proposition 5. The interaction effect of common ownership of the generic firms and the brand firm is negative. Therefore, higher levels of common ownership of the other generic firm make the effect of common ownership of the focal generic firm more negative.

\subsection{Empirical implementation and results}

Table 6 presents the results of specifications where we include a measure of common ownership for another generic entrant $G^{\prime}$ with the brand. We take a pragmatic approach and calculate $\delta^{\prime}$ as the level of common ownership between the brand in the market and the most experienced potential generic entrant. We reason that potential generic entrants are likely to consider the most experienced other potential generic entrant as a viable entry candidate, and hence are likely to take the common ownership of this firm with the brand into consideration. We identify the most experienced potential generic entrant as the firm that has the highest previous experience at the drug form/route level for the given drug market as measured by the variable Experience Route. ${ }^{33}$

Our results are in line with the theory outlined above. First, we find that the coefficient on $\delta$ is negative and significant for our three different ownership measures

\footnotetext{
${ }^{33}$ Since we consider a large set of potential entrants in our empirical analysis (on average 131 per market) it would not be feasible to include measures of $\delta^{\prime}$ for all other potential entrants. Moreover aggregating measures of $\delta^{\prime}$ for a large set of potential entrants is likely to provide a meaningless statistic; whereas for the econometrician it is difficult to restrict to the set of potential entrants based on observable characteristics, for generic entrants it may be more clear which other generics are candidates to enter a specific drug market.
} 
in all specifications. In other words, the main result of our basic framework still holds: higher levels of common ownership between the focal generic firm and the brand firm reduce the likelihood of entry.

Second, as can be seen from coefficients on $\delta^{\prime}$ in columns (1), (2) and (3), the overall impact of common ownership between the other potential generic entrant and the brand company, $\delta^{\prime}$, is positive; i.e. higher common ownership between $G^{\prime}$ and the brand increases the likelihood that $G$ enters on average. The logic is as follows: higher common ownership between $G^{\prime}$ and the brand reduces the likelihood of entry by $G^{\prime}$. This reduced likelihood of entry by $G^{\prime}$ in turn increases the likelihood of entry by the focal generic $G$. Therefore, entry decisions between generic companies $G$ and $G^{\prime}$ are characterised, on average, by strategic substitutabilities. Note, however, that these results are not very significant. This is perhaps not surprising, as we are measuring average effects that might hide heterogeneities in terms of strategic substitutability and complementarity.

Therefore, in a next step we include interaction effects $\delta \times \delta^{\prime}$ (see columns (4), (5) and (6)). The coefficient on the interaction term $\delta \times \delta^{\prime}$ is negative, although not signifcant. Thus, we find some evidence that higher levels of $G^{\prime}$ 's common ownership with brand, reinforces the negative effect of $G$ 's common ownership with brand.

To understand how common ownership influences entry decisions of generics to be strategic substitutes or complements, we perform a thought experiment on $\delta_{S}$ and $\delta_{S}^{\prime}$ and impose symmetry, i.e. $\delta_{S}=\delta_{S}^{\prime}=x$. The overall effect of $G^{\prime \prime}$ 's common ownership with the brand on $G$ 's probability of entry is positive if $0.009 x-0.02 x^{2}>0$, which can be re-written as $x<0.45$. Hence, for symmetric common ownership levels of $G$ and $G^{\prime}$ with the brand company, for lower levels of common ownership $(x<0.45), G^{\prime}$ 's common ownership with the brand has an overall positive effect on $G$ 's probability of entry (entrants are strategic substitutes). For higher levels common ownership $(x>0.45)$, $G^{\prime}$ 's common ownership with the brand has an overall negative effect on $G$ 's probability of entry. Thus, entry decisions are strategic complements. 


\begin{tabular}{|c|c|c|c|c|c|c|}
\hline & $(1)$ & $(2)$ & $(3)$ & $(4)$ & $(5)$ & $(6)$ \\
\hline$\delta_{S}$ & $\begin{array}{c}-0.0124^{* * *} \\
(0.00438)\end{array}$ & & & $\begin{array}{c}-0.0109^{* *} \\
(0.00475)\end{array}$ & & \\
\hline$\delta_{S}^{\prime}$ & $\begin{array}{c}0.00674 \\
(0.00512)\end{array}$ & & & $\begin{array}{l}0.00913^{*} \\
(0.00533)\end{array}$ & & \\
\hline$\delta_{S} \times \delta_{S}^{\prime}$ & & & & $\begin{array}{l}-0.0226 \\
(0.0269)\end{array}$ & & \\
\hline$\delta_{C}$ & & $\begin{array}{c}-0.0427^{* * *} \\
(0.0131)\end{array}$ & & & $\begin{array}{c}-0.0384^{* * *} \\
(0.0142)\end{array}$ & \\
\hline$\delta_{C}^{\prime}$ & & $\begin{array}{c}0.0118 \\
(0.0148)\end{array}$ & & & $\begin{array}{c}0.0182 \\
(0.0154)\end{array}$ & \\
\hline$\delta_{C} \times \delta_{C}^{\prime}$ & & & & & $\begin{array}{l}-0.182 \\
(0.194)\end{array}$ & \\
\hline$\delta_{L}$ & & & $\begin{array}{c}-0.0169^{* * *} \\
(0.00401)\end{array}$ & & & $\begin{array}{c}-0.0159^{* * *} \\
(0.00435)\end{array}$ \\
\hline$\delta_{L}^{\prime}$ & & & $\begin{array}{l}0.00910^{*} \\
(0.00534)\end{array}$ & & & $\begin{array}{c}0.0106^{*} \\
(0.00554)\end{array}$ \\
\hline$\delta_{L} \times \delta_{L}^{\prime}$ & & & & & & $\begin{array}{l}-0.0164 \\
(0.0252)\end{array}$ \\
\hline Subsidiary $(0 / 1)$ & $\begin{array}{c}-0.0412^{* * *} \\
(0.0102)\end{array}$ & $\begin{array}{c}-0.0406^{* * *} \\
(0.0102)\end{array}$ & $\begin{array}{c}-0.0412^{* * *} \\
(0.0102)\end{array}$ & $\begin{array}{c}-0.0412^{* * *} \\
(0.0102)\end{array}$ & $\begin{array}{c}-0.0406^{* * *} \\
(0.0102)\end{array}$ & $\begin{array}{c}-0.0412^{* * *} \\
(0.0102)\end{array}$ \\
\hline Sales Rank (1-10) (0/1) & $\begin{array}{c}0.0222^{* * *} \\
(0.00622)\end{array}$ & $\begin{array}{c}0.0221^{* * *} \\
(0.00622)\end{array}$ & $\begin{array}{c}0.0222^{* * *} \\
(0.00622)\end{array}$ & $\begin{array}{c}0.0221^{* * *} \\
(0.00622)\end{array}$ & $\begin{array}{c}0.0221^{* * *} \\
(0.00622)\end{array}$ & $\begin{array}{c}0.0222^{* * *} \\
(0.00621)\end{array}$ \\
\hline Sales Rank (11-50) (0/1) & $\begin{array}{c}0.0223^{* * *} \\
(0.00364)\end{array}$ & $\begin{array}{c}0.0224^{* * *} \\
(0.00364)\end{array}$ & $\begin{array}{c}0.0224^{* * *} \\
(0.00364)\end{array}$ & $\begin{array}{c}0.0222^{* * *} \\
(0.00364)\end{array}$ & $\begin{array}{c}0.0223^{* * *} \\
(0.00364)\end{array}$ & $\begin{array}{c}0.0224^{* * *} \\
(0.00364)\end{array}$ \\
\hline Sales Rank (51-100) (0/1) & $\begin{array}{c}0.0176^{* * *} \\
(0.00308)\end{array}$ & $\begin{array}{c}0.0177^{* * *} \\
(0.00308)\end{array}$ & $\begin{array}{c}0.0175^{* * *} \\
(0.00308)\end{array}$ & $\begin{array}{c}0.0176^{* * *} \\
(0.00308)\end{array}$ & $\begin{array}{c}0.0177^{* * *} \\
(0.00308)\end{array}$ & $\begin{array}{c}0.0175^{* * *} \\
(0.00308)\end{array}$ \\
\hline Authorized Generic $(0 / 1)$ & $\begin{array}{c}0.00102 \\
(0.00151)\end{array}$ & $\begin{array}{l}0.000980 \\
(0.00151)\end{array}$ & $\begin{array}{c}0.00107 \\
(0.00151)\end{array}$ & $\begin{array}{c}0.00103 \\
(0.00151)\end{array}$ & $\begin{array}{l}0.000991 \\
(0.00151)\end{array}$ & $\begin{array}{c}0.00108 \\
(0.00151)\end{array}$ \\
\hline Substitutes on Patent (ATC2) & $\begin{array}{c}-0.00449^{* *} \\
(0.00183)\end{array}$ & $\begin{array}{c}-0.00451^{* *} \\
(0.00184)\end{array}$ & $\begin{array}{c}-0.00441^{* *} \\
(0.00183)\end{array}$ & $\begin{array}{c}-0.00448^{* *} \\
(0.00184)\end{array}$ & $\begin{array}{c}-0.00449^{* *} \\
(0.00184)\end{array}$ & $\begin{array}{c}-0.00440^{* *} \\
(0.00183)\end{array}$ \\
\hline Substitutes off Patent (ATC2) & $\begin{array}{r}-0.000809 \\
(0.00152)\end{array}$ & $\begin{array}{r}-0.000796 \\
(0.00152)\end{array}$ & $\begin{array}{r}-0.000839 \\
(0.00152)\end{array}$ & $\begin{array}{c}-0.000814 \\
(0.00152)\end{array}$ & $\begin{array}{c}-0.000806 \\
(0.00152)\end{array}$ & $\begin{array}{r}-0.000846 \\
(0.00152)\end{array}$ \\
\hline Experience Route & $\begin{array}{c}0.00835^{* * *} \\
(0.000564)\end{array}$ & $\begin{array}{c}0.00834^{* * *} \\
(0.000564)\end{array}$ & $\begin{array}{c}0.00836^{* * *} \\
(0.000565)\end{array}$ & $\begin{array}{c}0.00835^{* * *} \\
(0.000564)\end{array}$ & $\begin{array}{c}0.00834^{* * *} \\
(0.000564)\end{array}$ & $\begin{array}{c}0.00836^{* * *} \\
(0.000564)\end{array}$ \\
\hline Experience ATC2 & $\begin{array}{c}0.0602^{* * *} \\
(0.00699)\end{array}$ & $\begin{array}{c}0.0602^{* * *} \\
(0.00699)\end{array}$ & $\begin{array}{c}0.0601^{* * *} \\
(0.00699)\end{array}$ & $\begin{array}{c}0.0602^{* * *} \\
(0.00699)\end{array}$ & $\begin{array}{c}0.0602^{* * *} \\
(0.00699)\end{array}$ & $\begin{array}{c}0.0601^{* * *} \\
(0.00699)\end{array}$ \\
\hline Experience New Drug & $\begin{array}{c}0.00437^{* *} \\
(0.00222)\end{array}$ & $\begin{array}{c}0.00433^{* *} \\
(0.00217)\end{array}$ & $\begin{array}{c}0.00478^{* *} \\
(0.00219)\end{array}$ & $\begin{array}{c}0.00438^{* *} \\
(0.00222)\end{array}$ & $\begin{array}{c}0.00434^{* *} \\
(0.00217)\end{array}$ & $\begin{array}{c}0.00479^{* *} \\
(0.00219)\end{array}$ \\
\hline Breadth (ATC2) & $\begin{array}{c}0.00325^{* * *} \\
(0.000920)\end{array}$ & $\begin{array}{c}0.00334^{* * *} \\
(0.000924)\end{array}$ & $\begin{array}{c}0.00330^{* * *} \\
(0.000920)\end{array}$ & $\begin{array}{c}0.00325^{* * *} \\
(0.000920)\end{array}$ & $\begin{array}{c}0.00333^{* * *} \\
(0.000924)\end{array}$ & $\begin{array}{c}0.00329^{* * *} \\
(0.000920)\end{array}$ \\
\hline Therapeutic field $(0 / 1)$ & Yes & Yes & Yes & Yes & Yes & Yes \\
\hline Drug form $(0 / 1)$ & Yes & Yes & Yes & Yes & Yes & Yes \\
\hline Submission type $(0 / 1)$ & Yes & Yes & Yes & Yes & Yes & Yes \\
\hline Generic region of origin $(0 / 1)$ & Yes & Yes & Yes & Yes & Yes & Yes \\
\hline Year end of exclusivity $(0 / 1)$ & Yes & Yes & Yes & Yes & Yes & Yes \\
\hline Constant & $\begin{array}{c}0.0300^{* * *} \\
(0.00676)\end{array}$ & $\begin{array}{c}0.0295^{* * *} \\
(0.00676)\end{array}$ & $\begin{array}{c}0.0296^{* * *} \\
(0.00675)\end{array}$ & $\begin{array}{c}0.0300^{* * *} \\
(0.00676)\end{array}$ & $\begin{array}{c}0.0295^{* * *} \\
(0.00676)\end{array}$ & $\begin{array}{c}0.0296^{* * *} \\
(0.00675)\end{array}$ \\
\hline Observations & 58,737 & 58,737 & 58,737 & 58,737 & 58,737 & 58,737 \\
\hline Drug markets & 451 & 451 & 451 & 451 & 451 & 451 \\
\hline R-squared & 0.079 & 0.079 & 0.079 & 0.079 & 0.079 & 0.079 \\
\hline
\end{tabular}

Notes: Standard errors in parentheses are robust. The dependent variable is entry within 18 months. $* * * p<$ $0.01, * * p<0.05, * p<0.1$.

Table 6: Multiple Entrants 


\section{Conclusion}

Ownership linkages between firms, which typically arise due to large institutional investors that invest in multiple firms in an industry, are a defining feature of firm ownership structures in the present day. Consequently the question of whether institutional investors influence firm strategies and correspondingly whether common ownership between rival firms has an effect on product markets outcomes has recently attracted significant attention.

In this paper we consider the effect of common ownership on market entry decisions in the pharmaceutical industry. Given that generic entry results in substantial revenue losses for the brand firm, a simple theory model shows that with common ownership, a potential generic entrant partly internalises the harm that entry inflicts on the incumbent and thus is less likely to enter. Empirical results lend robust support to this proposition. We show that higher common ownership between a potential generic entrant and the brand firm (incumbent) in a specific drug market has a significant negative effect on the likelihood that the generic firm will enter the market. Based on a linear probability model that relates generic entry to several measures of common ownership with the brand, we find that a one-standard-deviation increase in common ownership decreases the probability of generic entry by $9-13 \%$.

We further consider how common ownership between other rival generics and the brand may influence the focal generic firm's entry decision. We theoretically show that the classical result of entry decisions being strategic substitutes may be reversed into being strategic substitutes in the presence of high common ownership. We find some empirical evidence that this can indeed be the case.

This research contributes to the literature on the product markets effects of common ownership and informs the current debate on the influence of institutional investors. We provide evidence that is consistent with the hypothesis that common shareholders indeed influence strategic decisions of companies. Given the importance of generic entry in terms of reducing drug prices and therefore overall healthcare costs, common ownership in the pharmaceutical industry may have the potential to raise the costs to consumers and healthcare payors. 


\section{References}

Aghion, P., Van Reenen, J., \& Zingales, L. (2013). Innovation and institutional ownership. American economic review, 103(1), 277-304.

Angrist, J. D., \& Pischke, J.-S. (2009). Mostly harmless econometrics: An empiricist's companion. Princeton: Princeton University Press.

Antón, M., Ederer, F., Giné, M., \& Schmalz, M. C. (2018). Common ownership, competition, and top management incentives. Mimeo.

Antón, M., Ederer, F., Giné, M., \& Schmalz, M. C. (2017). Innovation: The bright side of common ownership?

Appel, I. R., Gormley, T. A., \& Keim, D. B. (2016). Passive investors, not passive owners. Journal of Financial Economics, 121(1), 111-141.

Appelt, S. (2015). Authorized generic entry prior to patent expiry: reassessing incentives for independent generic entry. Review of Economics and Statistics, 97(3 ), 654-666.

Azar, J., Raina, S., \& Schmalz, M. C. (2016). Ultimate ownership and bank competition.

Azar, J. (2017). Portfolio Diversification, Market Power and the Theory of the Firm. IESE Business School, Universidad de Navarra. Working Paper.

Azar, J., Schmalz, M. \&Tecu, I. (2018). Anti-competitive effects of common ownership. Journal of Finance, forthcoming.

Banal-Estanol, A., Seldeslachts, J. \& Vives, X. (2018). Common Ownership - Product Market Consequences of a Shift from Active to Passive Investors. Mimeo.

Bena, J., Ferreira, M. A., Matos, P., \& Pires, P. (2017). Are foreign investors locusts? The long-term effects of foreign institutional ownership. Journal of Financial Economics, 126(1), 122-146. 
Berger, A. N., Hasan, I., \& Zhou, M. (2010). The effects of focus versus diversification on bank performance: Evidence from Chinese banks. Journal of Banking 83 Finance, $34(7), 1417-1435$.

Boone, A.L. \& White, J.T. (2015). The effect of institutional ownership on firm transparency and information production. Journal of Financial Economics, 117(3), 508-533.

Booraem, G. (2013). Passive investors, not passive owners: A look at Vanguard's approach to proxy voting and corporate governance.

Branstetter, L., Chatterjee, C., \& Higgins, M. J. (2016). Regulation and welfare: evidence from paragraph IV generic entry in the pharmaceutical industry. The RAND Journal of Economics, 47(4), 857-890.

Brav, A., Jiang, W., Ma, S., \& Tian, X. (2016). How does hedge fund activism reshape corporate innovation? (No. w22273). National Bureau of Economic Research.

Brav, A., Jiang, W., Partnoy, F., \& Thomas, R. (2008). Hedge fund activism, corporate governance, and firm performance. The Journal of Finance, 63(4), 1729-1775.

Brito, D., Ribeiro, R., \& Vasconcelos, H. (2014). Measuring unilateral effects in partial horizontal acquisitions. International Journal of Industrial Organization, 33, 22-36.

Brito, D., Cabral, L., \& Vasconcelos, H. (2016). Competitive Effects of Partial Control in an Input Supplier.

Carleton, W. T., Nelson, J. M., \& Weisbach, M. S. (1998). The influence of institutions on corporate governance through private negotiations: Evidence from TIAA-CREF. The Journal of Finance, 53(4), 1335-1362.

Caudill, S. B. (1988). Practitioners corner: An advantage of the linear probability model over probit or logit. Oxford Bulletin of Economics and Statistics, 50(4), 425-427.

Cici, G., Gibson, S., \& Rosenfeld, C. M. (2015). Cross-company effects of common ownership: Dealings between borrowers and lenders with a common blockholder. 
Coffee, J. C. (1991). Liquidity versus control: The institutional investor as corporate monitor. Columbia law review, 91(6), 1277-1368.

Costa-Font, J., McGuire, A., \& Varol, N. (2014). Price regulation and relative delays in generic drug adoption. Journal of health economics, 38, 1-9.

Del Guercio, D. \& Hawkins, J. (1999). The motivation and impact of pension fund activism. Journal of financial economics, 52(3), 293-340.

Elhauge, E. (2016). Horizontal Shareholding. Harvard Law Review, 129:1267.

Fichtner, J., Heemskerk, E. M., \& Garcia-Bernardo, J. (2017). Hidden power of the Big Three? Passive index funds, re-concentration of corporate ownership, and new financial risk. Business and Politics, 19(2), 298-326.

Freeman, K. (2016). The Effects of Common Ownership on Customer-Supplier Relationships.

Geng H, Hau H, Lai S. (2017). Patent success, patent holdup, and the structure of property rights.

Gilje, E., Gormley, T. A., \& Levit, D. (2018). The rise of common ownership.

Gilo, D., Moshe, Y., \& Spiegel, Y. (2006). Partial cross ownership and tacit collusion. The RAND Journal of Economics, 37(1), 81-99.

Glowicka, E., Lorincz, S., Pesaresi, E., Romero, L. S., \& Verouden, V. (2009). Generic entry in prescription medicines in the EU: main characteristics, determinants and effects. Brussels: European Commission.

Gramlich, J., \& Grundl, S. (2017). Testing for Competitive Effects of Common Ownership.

Handelsblatt Global (2016). The Supposed Influence of Asset Managers.

Harford, J., Jenter, D., \& Li, K. (2011). Institutional cross-holdings and their effect on 
acquisition decisions. Journal of Financial Economics, 99(1), 27-39.

He, J. J., \& Huang, J. (2017). Product market competition in a world of crossownership: Evidence from institutional blockholdings. The Review of Financial Studies, 30(8), 2674-2718.

Hudson, J. (2000). Generic take-up in the pharmaceutical market following patent expiry: a multi-country study. International Review of Law and Economics, 20(2), 205-221.

Hurwitz, M. A., \& Caves, R. E. (1988). Persuasion or information? Promotion and the shares of brand name and generic pharmaceuticals. The Journal of Law and Economics, 31(2), 299-320.

Jacobo-Rubio, R., Turner, J., \& Williams, J. (2017). The Distribution of Surplus in the US Pharmaceutical Industry: Evidence from Paragraph (iv) Patent Litigation Decisions.

Kennedy, P., O'Brien, D. P., Song, M., \& Waehrer, K. (2017). The Competitive Effects of Common Ownership: Economic Foundations and Empirical Evidence.

Kyle, M. K. (2006). The role of firm characteristics in pharmaceutical product launches. The RAND Journal of Economics, 37(3), 602-618.

Lopez, A. L., \& Vives, X. (2017). Cross-ownership, R\&D spillovers, and antitrust policy.

Malenko, N., \& Shen, Y. (2016). The role of proxy advisory firms: Evidence from a regression-discontinuity design. The Review of Financial Studies, 29(12), 3394-3427.

McCahery, J. A., Sautner, Z., \& Starks, L. T. (2016). Behind the scenes: The corporate governance preferences of institutional investors. The Journal of Finance, 71(6), 2905-2932.

Moreno-Torres, I., Puig-Junoy, J., \& Borrell, J. R. (2009). Generic entry into the regulated Spanish pharmaceutical market. Review of Industrial Organization, 34(4), 373-388. 
New York Times (2016). Rise of Institutional Investors Raises Questions of Collusion.

O'Brien, D. P., \& Salop, S. C. (1999). Competitive effects of partial ownership: Financial interest and corporate control. Antitrust Law Journal, 67, 559.

O'Brien, D. P., \& Waehrer, K. (2017). The Competitive Effects of Common Ownership: We Know Less Than We Think.

OECD (2017). Policy Roundtable: Common ownership by institutional investors and its impact on competition.

Ojeda, W. (2017). Common ownership in the loan market.

Patel, M. (2017). Common Ownership, Institutional Investors, and Antitrust. Antitrust Law Journal, forthcoming.

Posner, E. A., Scott Morton, F. M., \& Weyl, E. G. (2017). A proposal to limit the anti-competitive power of institutional investors. Antitrust Law Journal, forthcoming.

Regan, T. L. (2008). Generic entry, price competition, and market segmentation in the prescription drug market. International Journal of Industrial Organization, 26(4), 930-948.

Reiffen, D., \& Ward, M. R. (2005). Generic drug industry dynamics. The Review of Economics and Statistics, 87(1), 37-49.

Reynolds, R. J., \& Snapp, B. R. (1986). The competitive effects of partial equity interests and joint ventures. International Journal of Industrial Organization, 4(2), 141-153.

Rotemberg J. (1984). Financial transaction costs and industrial performance. Working Paper, Alfred P. Sloan School of Management.

Rubinstein, A. \& Yaari M.E. (1983). The competitive stock market as cartel maker: Some examples. Suntory and Toyota International Centres for Economics and Related 
Disciplines, LSE

Saha, A., Grabowski, H., Birnbaum, H., Greenberg, P., \& Bizan, O. (2006). Generic competition in the US pharmaceutical industry. International Journal of the Economics of Business, 13(1), 15-38.

Schmalz, M. (2015). How Passive Funds Prevent Competition.

Schmalz, M. C. (2018). Common Ownership Concentration and Corporate Conduct. Schmidt, C., \& Fahlenbrach, R. (2017). Do exogenous changes in passive institutional ownership affect corporate governance and firm value? Journal of Financial Economics, 124(2), 285-306.

Scott Morton, F. M. (1999). Entry decisions in the generic pharmaceutical industry. The Rand Journal of Economics, 421-440.

Scott Morton, F. M. (2000). Barriers to entry, brand advertising, and generic entry in the US pharmaceutical industry. International Journal of Industrial Organization, 18(7), 1085-1104

Scott Morton, F. M. (2002). Horizontal integration between brand and generic firms in the pharmaceutical industry. Journal of Economics $\&$ Management Strategy, 11(1), 135-168.

Seldeslachts, J., Newham, M., \& Banal-Estanol, A. (2017). Common ownership of German companies. DIW Economic Bulletin 30.

The Economist (2015). Mutual funds and airline competition: Who really owns the skies?

Xie, J., \& Gerakos, J. (2018). Institutional cross-holdings and generic entry in the pharmaceutical industry. 


\section{Appendix on dataset construction}

This Appendix contains a detailed description of how the data used for the analysis in this paper was constructed. The FDA Orange Book was downloaded from the FDA website in 2017q2. First duplicate applications in the FDA Orange Book were identified and removed. Where duplicate applications had different approval dates, the earlier date was taken. Thereafter the products in the dataset were merged with historical patent data from the FDA based on the FDA drug application number and product number. The patent data provides a complete list of which patents are associated with the product and their corresponding expiration dates.

In the FDA Orange Book, a drug product (which is thus equal to the "relevant product market") can be identified as a unique ingredient-form-strength combination. For example, Cetirizine Hydrochloride in syrup form with a strength of $5 \mathrm{mg} / 5 \mathrm{ml}$.

Initially, the FDA Orange Book reports 3964 products at the ingredient-form-strength level that were launched from 1982q1 until 2017q2. For our purposes we restricted the data in multiple ways. First, we consider only drug products that faced generic entry or patent expiry in the time frame $2004 q 1$ to $2014 q 4$ (this is the range where we have data on all variables). This results in a sample of 1080 unique drug products. We then drop drug products which are not linked to any patent (since this study focuses on market entry in markets that are initially protected by patents). This results in 666 unique drug products. Thereafter we drop OTC drugs, keeping only prescription drugs. This results in 640 unique drug products.

On the basis of information contained in the Orange Book we seek to remove product markets were the original brand drug was withdrawn for safety reasons. We identify these markets as markets where the original brand has been discontinued, there is no note in the Orange Book that the discontinuation was not for safety reasons. Dropping these markets results in 554 product markets. We drop two further product markets where generic applications (ANDAs) are approved before the NDA application for the same ingredient-form-strength. This results in 552 product markets.

We then aggregate these product markets to the ingredient-form level. We take the first strength that was approved by the FDA at the ingredient-form level as the relevant brand product. We then identify subsequent ANDAs that were approved at the same ingredient-form level. In cases where a generic enters with multiple strengths, we keep only the earliest entry. This results in 457 unique product markets, or brand products, at the ingredient-form level.

A variable is constructed that takes the earlier of either generic entry or the date of the last expiring patent for the relevant product market at the ingredient-form level; call this date the "end of exclusivity". In line with the literature, we merge in annual drug sales data from one year before the end of exclusivity. The sales data is obtained from drugs.com. Drugs.com provides the annual US sales figures for the top 200 drugs for the years 2003 - 2010 (source: Verispan/ VONA) and the top 100 drugs for the years 2011 - 2013 (source: IMS Health/Midas). Out the sample of 457 product markets, 131 product markets at the ingredient-form level can be matched with sales data.

The sales data is matched with the FDA Orange book on the basis of trade name. Whereas in some cases the trade name provides an indication of which dosage form the sales refer to, in most cases we have just the trade name of the product. Hence for drugs which are offered in different forms, the different forms are each matched with the total sales of the product. In total there are 160 drug product markets which are available in different forms. One ingredient may be offered in as many as 4 different forms (e.g. tablet; oral, for suspension, oral; capsule, oral; injectable, injection). If we 
chose to only keep one form per ingredient we would drop 92 product markets. Of the drugs which are matched to sales data, there are 68 product markets where the ingredient is available in different forms.

Each product is linked through exact text matching, based on compound-name, with the ATC/DDD Index 2015. The ATC/DDD Index 2015 is used to identify relevant therapeutic markets and chemical classes for different levels of the ATC classification system. Whereas the ATC-3 level is most in line with market definition in M\&A approval procedures in Europe and the United States, through the matching process one drug may be linked with numerous therapeutic classes at the ATC-3 level. To ensure that we obtain a unique therapeutic for each drug, we use the broader market definition of ATC-2.

For each product market, we identify if the brand firm has launched its own generic in the market (an "authorised generic") using the FDA list of authorised generics. The merge was conducted on the basis of trade name and form. Additional information, such as submission class, is merged in using the FDA application number. We recode the FDA form/route variable to construct five form/route classes namely oral, injection, topical, ophthalmic and inhalation.

The current online version of the FDA Orange Book suffers from partial back-dating of company names to reflect the current manufacturer of the drug. To correct for this we downloaded previous versions of the Orange Book (2001q4, 2002q4,..., 2014q4) using Internet Archive. Using information from previous versions of the Orange Book, we determine the company name of the generic company at approval and the name of brand company at the end of exclusivity.

The data on firms and their product launches from the FDA Orange book is then matched with the Thomson Reuters ownership dataset based on the name of the pharmaceutical company. We correct for the fact that firms may change their name over the course of the sample period and undergo mergers, on the basis of public information.

Based on public information we record the year-quarters in which each firm is either publicly listed or not. For example, some companies in the sample start out being publicly listed, and then are taken off the stock exchange (for example, if they experience a leveraged buyout) and then are later made public again. It can occur that a company that is known to have been public in a specific year-quarter, has no ownership information in this year-quarter in the Thomson Reuters dataset. Where we have a public firm in the pair that has missing ownership data we remove this pair from the analysis. A total 6 product markets are dropped due to missing ownership data, resulting in 451 product markets.

Subsidiary firms are assigned the ownership structure of the parent firm under the assumption that they are fully controlled by the parent. However in recognition of the fact that the subsidiary is a separate entity from the parent with its own previous experience, we determine all experience variables at the subsidiary level. That is, we do not assign the experience of the parent to the subsidiary. There are 43 unique pairs where the relationship between the brand and potential generic entrant is that of parent and subsidiary.

We are also able to identify cross ownership links in the data, that is, where one firm has an ownership stake of less than $50 \%$ in another firm. There are three pairs in the dataset where the brand has a stake-holding in the potential generic entrant for some time periods (Daiichi-Ranbaxy, Galderma-Alcon and Novartis-Alcon). There is one pair where the potential generic entrant has a stake-holding in the brand (Taro-Sun).

In total there are 102 unique brand companies (77 of which are publicly listed at some point in time) and 145 unique generic companies (69 of which are publicly listed at some point in time) operating 
within the relevant markets and time period. Given that the focus of the paper is on links between brand and generic companies, we make our dataset pairwise: brand-generic pair; there are 13,954 unique pairs.

The common ownership measures are constructed at the pair level using data from Thomson Reuters Global Ownership Database from 2003 to 2014. We calculate common ownership measures in the year of the end of exclusivity (lag 0 ), one year prior (lag 1) and two years prior (lag 2). When constructing measures of common ownership, we restrict ourselves to the investor holdings that represent at least one percent in the equity of the firms. Investor acquisitions during this period and ultimate owners are identified on the basis of public sources. 


\section{Appendix on common ownership}

There is more and more evidence that institutional investors influence governance, policies and strategic decisions of firms (e.g., Aghion et al., 2013; Brav et al., 2008; Brav et al., 2016). But this evidence often focuses on the role of active fund managers, such as hedge funds (some evidence). The literature proposes two channels through which large investors can affect corporate decisions: Voice and exit. Both channels appear at first sight not suited for passive investors, who do not actively buy or sell shares.

The voice channel, where investors actively interact with management to discuss their preferences, looks expensive for low-cost passive institutional investors that cover literally thousands of stocks. This argument becomes stronger when considering that passive investors are typically more diversified and thus have less resources to spend per firm in their portfolio. The exit channel is not available to index-tracking investors who follow often indices like the S\&P 500, and who are additionally mostly paid by minimising the tracking error with these indices. Moreover, one might argue that passive institutional investors might lack the incentives to monitor as they seek to deliver the performance of a benchmark, and not of an in individual firm.

But there are several reasons why the growth of passive investors might lead to a higher influence in firms' decisions, and not lower. First, passive investors are less willing, or are more restricted, to divest their positions in poorly performing stocks since they follow an index. Therefore, they might be more motivated than other institutions to be engaged owners (e.g., Carleton et al., 1998). Furthermore, passive institutional investors insist that they have a fiduciary duty to weigh in on firms' decisions and do so through informal meetings with management and through voting at annual general meetings by the employment, for example, of proxy voters such as Institutional Shareholder Services (ISS) (Malenko and Shen, 2016). Managers might actually be more inclined to listen to passive investors, as their stakes are sizeable and tend to exhibit lower turnover rates (Del Guercio and Hawkins, 1999). Indeed, anecdotal evidence in Appel et al. (2016) suggests that informal discussions between passive institutions and managers, backed with the threat of voice (i.e., voting in shareholding meetings), are often used to exert influence. ${ }^{34}$

Some commentators worry that passive investors lack the motives and resources to monitor their large, diverse portfolios, and that the increasing market share of those investors weakens firm-level performance. ${ }^{35}$ Others, however, assert that passive investors is something very different from passive owners. ${ }^{36}$

Using an IV approach to account for correlations between passive investment and companies' choices, Appel et al. (2016) find that passive mutual funds have a significant and positive impact

\footnotetext{
${ }^{34}$ Glenn Booraem, controller of Vanguard funds, notes that engagement with directors and management of companies is a key component and that Vanguard has "found through hundreds of discussions every year" that it is "frequently able to accomplish as much -or much more through dialogue " as through voting (Booraem, 2014).

${ }^{35}$ A quote from the Economist (2015) on February 7, taken from Appel et al. (2016), expresses this view: "A rising chunk of the stock market sits in the hands of lazy investors. Index funds and exchange-traded funds mimic the market's movements, and typically take little interest in how firms are run; conventional mutual funds and pension funds that oversee diversified portfolios dislike becoming deeply involved in firms' management."

${ }^{36}$ See, for example, an article in the Financial Times on April 6 2014, by Rakhi Kumar, head of corporate governance at State Street Global (a passive institutional investor), titled "Passive investment, active ownership."
} 
on several aspects of corporate governance (board composition, anti-takover provisions and unequal voting rights). Their evidence further suggests that a key mechanism by which passive investors exert their influence is through their large voting blocks. Furthermore, long-term passive ownership leads to an increase in firms' returns on assets and Tobin's Q (but no change in firms' investments).

Boone and White (2015) examine the effects of institutional ownership on firm transparency and information production. They find that higher institutional ownership is associated with greater management disclosure; resulting in lower informational asymmetries. Interestingly, and in line with the findings of Appel et al. (2016), they find that indexing investors have the highest influence on information production. Thus, their evidence illustrates that indexing institutions can provide positive informational effects, which contrasts with claims that passive investors offer few benefits (Coffee, 1991).

Large institutional investors confirm that they want to influence companies' corporate policies and strategies. For example, Vanguard's chairman recently stated that Vanguard seeks active interactions with firms they invest in: "In the past, some have mistakenly assumed that our predominantly passive management style suggests a passive attitude with respect to corporate governance. Nothing could be further from the truth." 37 A similar message emerges from BlackRock's chairman Larry Fink, "We are an active voice, we work with companies, we need to work for the long-term interest." ${ }^{38}$

Specifically in pharmaceutical markets, institutional investors can be seen to take an active interest in the strategic decisions of companies. In 2016, a group of representatives of major US mutual funds (Fidelity Investments, T. Rowe Price Group Inc., Wellington Management Co., among others) met up with top biotechnology and pharmaceutical executives and lobbyists to discuss the pricing conditions of the market and the possible steps that could be taken in order to avoid future regulations. This example also illustrates that investor interactions need not be addressed to a particular company but can be extended to a specific industry. ${ }^{39}$

\footnotetext{
${ }^{37}$ Letter sent by F. William McNabb III, Vanguard's Chairman and CEO, to the independent leaders of the boards of directors of the Vanguard funds' largest portfolio holdings, dated 27 February 2015, available at https://about.vanguard.com/vanguard-proxy-voting/CEO Letter 0302 ext.pdf.

${ }^{38}$ Wall Street Journal, 'BlackRock's Larry Fink: typical activists are too short-term', dated 16 January 2014, available at http://blogs.wsj.com/moneybeat/2014/01/16/blackRocks-larry-finktypical-activists-are-too- short-term/

${ }^{39}$ Chen, C. (2016). Mutual fund industry to drug makers: stand up and defend yourself. Bloomberg News. Retrieved from https://www.bostonglobe.com/business/2016/05/10/mutual-fundindustry-drugmakers-stand-and-defend-yourself/REKxLITGDeQR2oVmUZaTIP/story.html
} 


\section{Appendix: IHE Index}

Figure 3: iShares U.S. Pharmaceutical (IHE) ETF

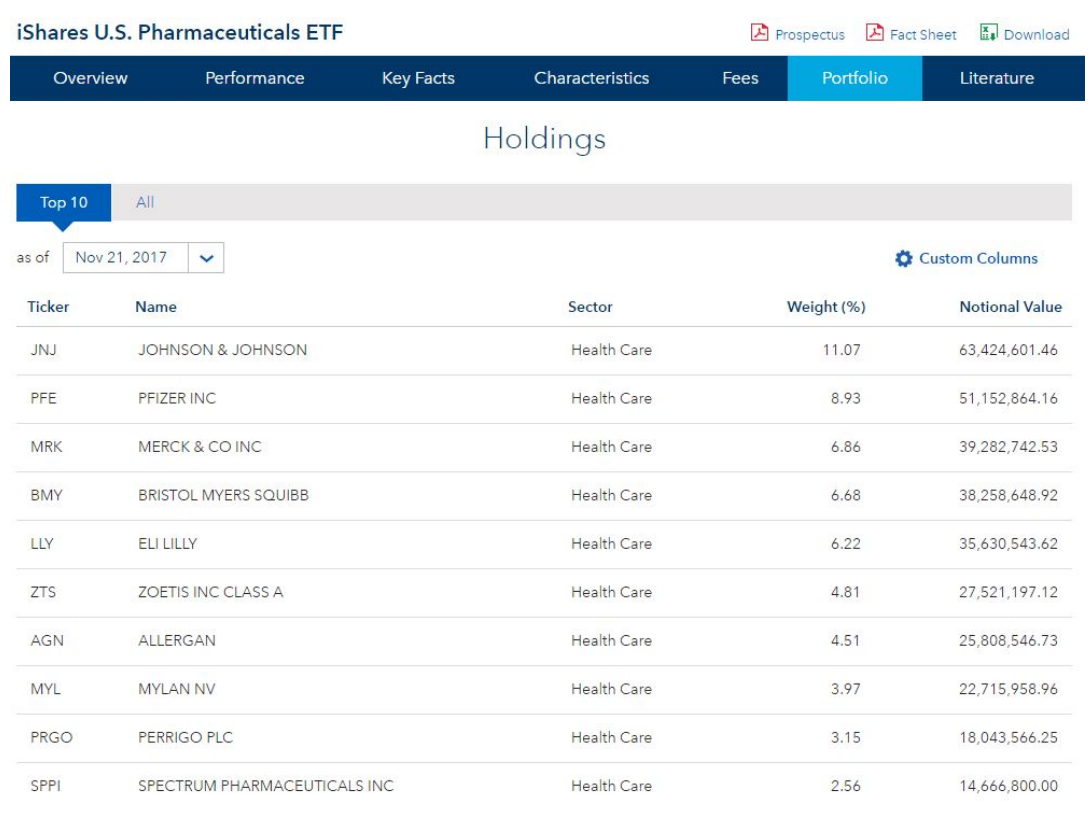

Figure 4: Comparison of Dow Jones Pharma Index and IHE returns

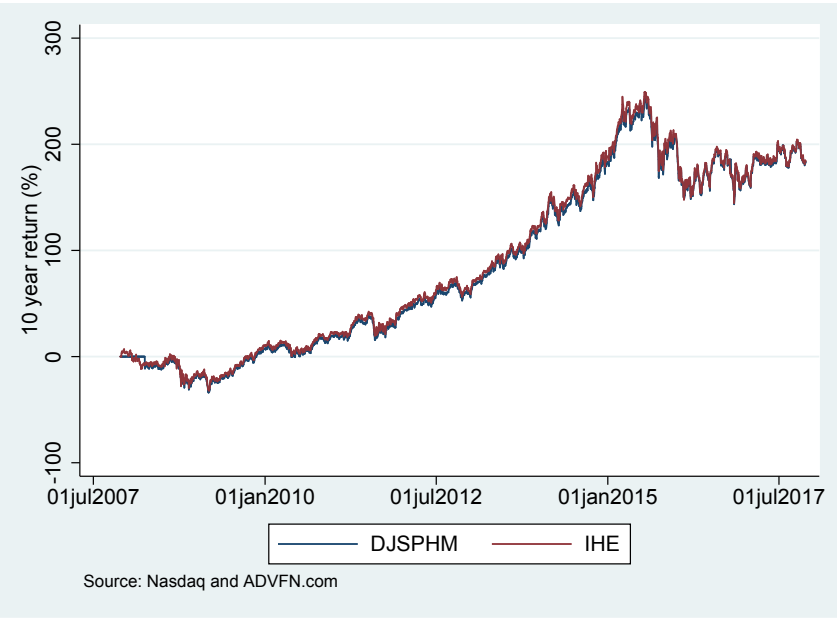




\section{Appendix: Top common investors by region}

\begin{tabular}{lcllllll}
\hline \hline \multicolumn{1}{c}{ Southern Asia } & & & \multicolumn{2}{c}{ Eastern Asia } & & \multicolumn{2}{c}{ Northern Europe } \\
\cline { 1 - 2 } Life Insurance of India & 12 & & Bank of Tokyo-Mitsubishi & 7 & & BlackRock & 6 \\
Citigroup & 7 & & Nomura Holdings & 6 & & Invesco & 5 \\
La Caixa & 7 & & Nippon Life Insurance & 6 & & Aviva & 5 \\
fil investment management & 7 & & Sumitomo Life Insurance & 4 & & NBIM & 5 \\
HDFC Asset Mgmt & 6 & & Nikko Asset Mgmt & 4 & & HarbourVest Partners & 5
\end{tabular}

\begin{tabular}{lcccc}
\multicolumn{1}{c}{ Western Europe } & & & \multicolumn{2}{c}{ Northern America } \\
\cline { 5 - 6 } BlackRock & 10 & & BlackRock & 65 \\
Fidelity Investments & 9 & & Sanguard Group & 59 \\
NBIM & 8 & & Northern Trust Global & 45 \\
HarbourVest Partners & 6 & & Fidelity Investments & 42 \\
Franklin Templeton & 6 & &
\end{tabular}

Table 7: Top common owners in each region for pharmaceutical firms and their number of blockholdings $>1 \%$ (2009) 


\section{Appendix: First-Stage}

\begin{tabular}{lccc}
\hline \hline & $(1)$ & $(2)$ & $(3)$ \\
& $\delta_{S}$ & $\delta_{C}$ & $\delta_{L}$ \\
\hline & & & \\
Index Periods & $0.0527^{* * *}$ & $0.0207^{* * *}$ & $0.0652^{* * *}$ \\
& $(0.000822)$ & $(0.000331)$ & $(0.00101)$ \\
Same Region & $0.0103^{* * *}$ & $0.00635^{* * *}$ & $0.00614^{* * *}$ \\
& $(0.00143)$ & $(0.000495)$ & $(0.00157)$ \\
Constant & $0.0776^{* * *}$ & $0.0197^{* * *}$ & $0.0547^{* * *}$ \\
& $(0.00701)$ & $(0.00218)$ & $(0.00676)$ \\
Observations & & & \\
Drug markets & 58,737 & 58,737 & 58,737 \\
R-squared & 451 & 451 & 451 \\
Fixed Effects & 0.285 & 0.298 & 0.293 \\
F-Test & Yes & Yes & Yes \\
F-Test (p-val) & 156.7 & 110.7 & 115 \\
Weak Instrument & 0 & 0 & 0 \\
Endogeneity test (p-val) & 0.276 & 0.445 & 2215 \\
\hline \hline
\end{tabular}

Notes: Standard errors in parentheses are robust. For simplicity only the coefficients associated with the excluded instruments are reported. $* * * p<$ $0.01, * * p<0.05, * p<0.1$.

Table 8: First-stage IV regressions 


\section{Appendix: Additional measures of common ownership}

$$
\begin{gathered}
\delta_{M}=\sum_{j=1}^{M} \max \left(\gamma_{j B} ; \gamma_{j G}\right) \\
\delta_{G}=\sum_{j=1}^{M} \sqrt{\gamma_{j B}+\gamma_{j G}} \\
\delta_{H}=\sum_{j=1}^{M} \frac{\gamma_{j B} \times \gamma_{j G}}{\gamma_{j B}+\gamma_{j G}}
\end{gathered}
$$

where $j=1, \ldots, M$ are the investors that $B$ and $G$ have in common. $\gamma_{j B}$ is the size of the shareholding of investor $j$ in the brand (e.g. $5 \%$ ) and $\gamma_{j G}$ is the size of the shareholding of investor $j$ in the generic. The measure $\delta_{H}$ is a variant of the measure used by Harford et al. (2011). 


\section{Appendix: Robustness}

\begin{tabular}{|c|c|c|c|c|c|c|}
\hline & \multicolumn{3}{|c|}{ Probit } & \multicolumn{3}{|c|}{ Logit } \\
\hline & $(1)$ & $(2)$ & $(3)$ & (4) & $(5)$ & (6) \\
\hline \multirow[t]{2}{*}{$\delta_{S}$} & $-0.257^{* *}$ & & & $-0.573^{* *}$ & & \\
\hline & $(0.100)$ & & & $(0.224)$ & & \\
\hline \multirow[t]{2}{*}{$\delta_{C}$} & & $-0.773^{* * *}$ & & & $-1.879^{* * *}$ & \\
\hline & & $(0.298)$ & & & $(0.666)$ & \\
\hline \multirow[t]{2}{*}{$\delta_{L}$} & & & $-0.271^{* * *}$ & & & $-0.697^{* * *}$ \\
\hline & & & $(0.104)$ & & & $(0.230)$ \\
\hline \multirow[t]{2}{*}{ Subsidiary $(0 / 1)$} & $-0.948^{*}$ & $-0.935^{*}$ & $-0.937^{*}$ & $-2.297^{* *}$ & $-2.258^{* *}$ & $-2.271^{* *}$ \\
\hline & $(0.490)$ & $(0.489)$ & $(0.489)$ & $(1.089)$ & $(1.087)$ & $(1.087)$ \\
\hline \multirow[t]{2}{*}{ Sales Rank (1-10) (0/1) } & $0.330^{* * *}$ & $0.330^{* * *}$ & $0.328^{* * *}$ & $0.846^{* * *}$ & $0.848^{* * *}$ & $0.845^{* * *}$ \\
\hline & $(0.0862)$ & $(0.0861)$ & $(0.0862)$ & $(0.192)$ & $(0.191)$ & $(0.191)$ \\
\hline \multirow[t]{2}{*}{ Sales Rank (11-50) (0/1) } & $0.331^{* * *}$ & $0.330^{* * *}$ & $0.332^{* * *}$ & $0.780^{* * *}$ & $0.778^{* * *}$ & $0.783^{* * *}$ \\
\hline & $(0.0534)$ & $(0.0534)$ & $(0.0534)$ & $(0.121)$ & $(0.121)$ & $(0.121)$ \\
\hline \multirow[t]{2}{*}{ Sales Rank (51-100) (0/1) } & $0.311^{* * *}$ & $0.312^{* * *}$ & $0.310^{* * *}$ & $0.712^{* * *}$ & $0.717^{* * *}$ & $0.712^{* * *}$ \\
\hline & $(0.0485)$ & $(0.0485)$ & $(0.0485)$ & $(0.110)$ & $(0.110)$ & $(0.110)$ \\
\hline \multirow[t]{2}{*}{ Authorized Generic $(0 / 1)$} & 0.0549 & 0.0551 & 0.0554 & 0.0937 & 0.0932 & 0.0937 \\
\hline & $(0.0347)$ & $(0.0347)$ & $(0.0347)$ & $(0.0793)$ & $(0.0792)$ & $(0.0792)$ \\
\hline \multirow[t]{2}{*}{ Substitutes on Patent (ATC2) } & $-0.0939 * *$ & $-0.0943^{* *}$ & $-0.0935^{* *}$ & $-0.187^{* *}$ & $-0.187^{* *}$ & $-0.186^{* *}$ \\
\hline & $(0.0402)$ & $(0.0402)$ & $(0.0402)$ & $(0.0896)$ & $(0.0896)$ & $(0.0894)$ \\
\hline \multirow[t]{2}{*}{ Substitutes off Patent (ATC2) } & -0.0115 & -0.0102 & -0.0116 & -0.0370 & -0.0348 & -0.0380 \\
\hline & $(0.0438)$ & $(0.0438)$ & $(0.0438)$ & $(0.103)$ & $(0.103)$ & $(0.103)$ \\
\hline \multirow[t]{2}{*}{ Experience Route } & $0.0532^{* * *}$ & $0.0530 * * *$ & $0.0533^{* * *}$ & $0.0977 * * *$ & $0.0975^{* * *}$ & $0.0984^{* * *}$ \\
\hline & $(0.00421)$ & $(0.00420)$ & $(0.00423)$ & $(0.00904)$ & $(0.00902)$ & $(0.00913)$ \\
\hline \multirow[t]{2}{*}{ Experience ATC2 } & $0.419^{* * *}$ & $0.419^{* * *}$ & $0.419^{* * *}$ & $0.736^{* * *}$ & $0.737^{* * *}$ & $0.736^{* * *}$ \\
\hline & $(0.0461)$ & $(0.0461)$ & $(0.0461)$ & $(0.101)$ & $(0.101)$ & $(0.101)$ \\
\hline \multirow[t]{2}{*}{ Experience New Drug } & $-0.0824^{* *}$ & $-0.0840^{* *}$ & $-0.0800^{* *}$ & $-0.212^{* * *}$ & $-0.210^{* * *}$ & $-0.198^{* *}$ \\
\hline & $(0.0359)$ & $(0.0356)$ & $(0.0358)$ & $(0.0796)$ & $(0.0792)$ & $(0.0795)$ \\
\hline \multirow[t]{2}{*}{ Breadth (ATC2) } & $0.237^{* * *}$ & $0.237^{* * *}$ & $0.236^{* * *}$ & $0.615^{* * *}$ & $0.616^{* * *}$ & $0.613^{* * *}$ \\
\hline & $(0.0156)$ & $(0.0156)$ & $(0.0155)$ & $(0.0358)$ & $(0.0359)$ & $(0.0358)$ \\
\hline Therapeutic field $(0 / 1)$ & Yes & Yes & Yes & Yes & Yes & Yes \\
\hline Drug form $(0 / 1)$ & Yes & Yes & Yes & Yes & Yes & Yes \\
\hline Submission type $(0 / 1)$ & Yes & Yes & Yes & Yes & Yes & Yes \\
\hline Generic region of origin $(0 / 1)$ & Yes & Yes & Yes & Yes & Yes & Yes \\
\hline Year end of exclusivity $(0 / 1)$ & Yes & Yes & Yes & Yes & Yes & Yes \\
\hline \multirow[t]{2}{*}{ Constant } & $-2.271^{* * *}$ & $-2.278^{* * *}$ & $-2.280^{* * *}$ & $-4.516^{* * *}$ & $-4.522^{* * *}$ & $-4.528^{* * *}$ \\
\hline & $(0.226)$ & $(0.226)$ & $(0.226)$ & $(0.563)$ & $(0.563)$ & $(0.563)$ \\
\hline Observations & 57,835 & 57,835 & 57,835 & 57,835 & 57,835 & 57,835 \\
\hline Drug Markets & 451 & 451 & 451 & 451 & 451 & 451 \\
\hline
\end{tabular}

Notes: Standard errors in parentheses are robust. The dependent variable is entry within 18 months. The instruments are the number of periods listed in the ETF iShares U.S. Pharmaceutical (IHE) and an indicator variable that takes on the value 1 when the main headquarters of both companies are located in the same region. $* * * p<0.01, * * p<0.05, * p<0.1$.

Table 9: Robustness - Probit and Logit Estimations of Main Specification 


\begin{tabular}{|c|c|c|}
\hline & Probit & Logit \\
\hline$\delta_{S}(0<\delta \leq 0.3)$ & $\begin{array}{c}0.0498 \\
(0.0333)\end{array}$ & $\begin{array}{c}0.0988 \\
(0.0769)\end{array}$ \\
\hline$\delta_{S}(0.3<\delta \leq 0.5)$ & $\begin{array}{l}-0.0773 \\
(0.0537)\end{array}$ & $\begin{array}{l}-0.135 \\
(0.117)\end{array}$ \\
\hline$\delta_{S}(\delta>0.5)$ & $\begin{array}{c}-0.174^{* *} \\
(0.0843)\end{array}$ & $\begin{array}{c}-0.411^{* *} \\
(0.181)\end{array}$ \\
\hline Subsidiary $(0 / 1)$ & $\begin{array}{l}-0.912^{*} \\
(0.490)\end{array}$ & $\begin{array}{c}-2.202^{* *} \\
(1.090)\end{array}$ \\
\hline Sales Rank (1-10) (0/1) & $\begin{array}{c}0.330^{* * *} \\
(0.0862)\end{array}$ & $\begin{array}{c}0.848^{* * *} \\
(0.191)\end{array}$ \\
\hline Sales Rank (11-50) (0/1) & $\begin{array}{c}0.334^{* * *} \\
(0.0534)\end{array}$ & $\begin{array}{c}0.786^{* * *} \\
(0.121)\end{array}$ \\
\hline Sales Rank (51-100) (0/1) & $\begin{array}{c}0.310^{* * *} \\
(0.0486)\end{array}$ & $\begin{array}{c}0.709^{* * *} \\
(0.110)\end{array}$ \\
\hline Authorized Generic (0/1) & $\begin{array}{l}0.0587^{*} \\
(0.0347)\end{array}$ & $\begin{array}{c}0.102 \\
(0.0792)\end{array}$ \\
\hline Substitutes on Patent (ATC2) & $\begin{array}{c}-0.0931^{* *} \\
(0.0402)\end{array}$ & $\begin{array}{l}-0.185^{* *} \\
(0.0895)\end{array}$ \\
\hline Substitutes off Patent (ATC2) & $\begin{array}{l}-0.0140 \\
(0.0437)\end{array}$ & $\begin{array}{l}-0.0430 \\
(0.103)\end{array}$ \\
\hline Experience Route & $\begin{array}{c}0.0537^{* * *} \\
(0.00425)\end{array}$ & $\begin{array}{c}0.0985^{* * *} \\
(0.00910)\end{array}$ \\
\hline Experience ATC2 & $\begin{array}{c}0.419^{* * *} \\
(0.0460)\end{array}$ & $\begin{array}{c}0.738^{* * *} \\
(0.101)\end{array}$ \\
\hline Experience New Drug & $\begin{array}{c}-0.0908^{* *} \\
(0.0357)\end{array}$ & $\begin{array}{c}-0.228^{* * *} \\
(0.0792)\end{array}$ \\
\hline Breadth (ATC2) & $\begin{array}{c}0.231^{* * *} \\
(0.0159)\end{array}$ & $\begin{array}{c}0.601^{* * *} \\
(0.0370)\end{array}$ \\
\hline Therapeutic field $(0 / 1)$ & Yes & Yes \\
\hline Drug form $(0 / 1)$ & Yes & Yes \\
\hline Submission type $(0 / 1)$ & Yes & Yes \\
\hline Generic region of origin $(0 / 1)$ & Yes & Yes \\
\hline Year end of exclusivity $(0 / 1)$ & Yes & Yes \\
\hline Constant & $\begin{array}{c}-2.294^{* * *} \\
(0.227)\end{array}$ & $\begin{array}{c}-4.559^{* * *} \\
(0.565)\end{array}$ \\
\hline Observations & 57,835 & 57,835 \\
\hline $\begin{array}{l}\text { Drug markets } \\
\text { R-squared }\end{array}$ & 451 & 451 \\
\hline
\end{tabular}

Notes: Standard errors in parentheses are robust. The dependent variable is entry within 18 months. The instruments are the number of periods listed in the ETF iShares U.S. Pharmaceutical (IHE) and an indicator variable that takes on the value 1 when the main headquarters of both companies are located in the same region. $* * * p<0.01, * * p<0.05, * p<0.1$.

Table 10: Robustness - Logit and Probit Estimations of Categorical Variables Specification 


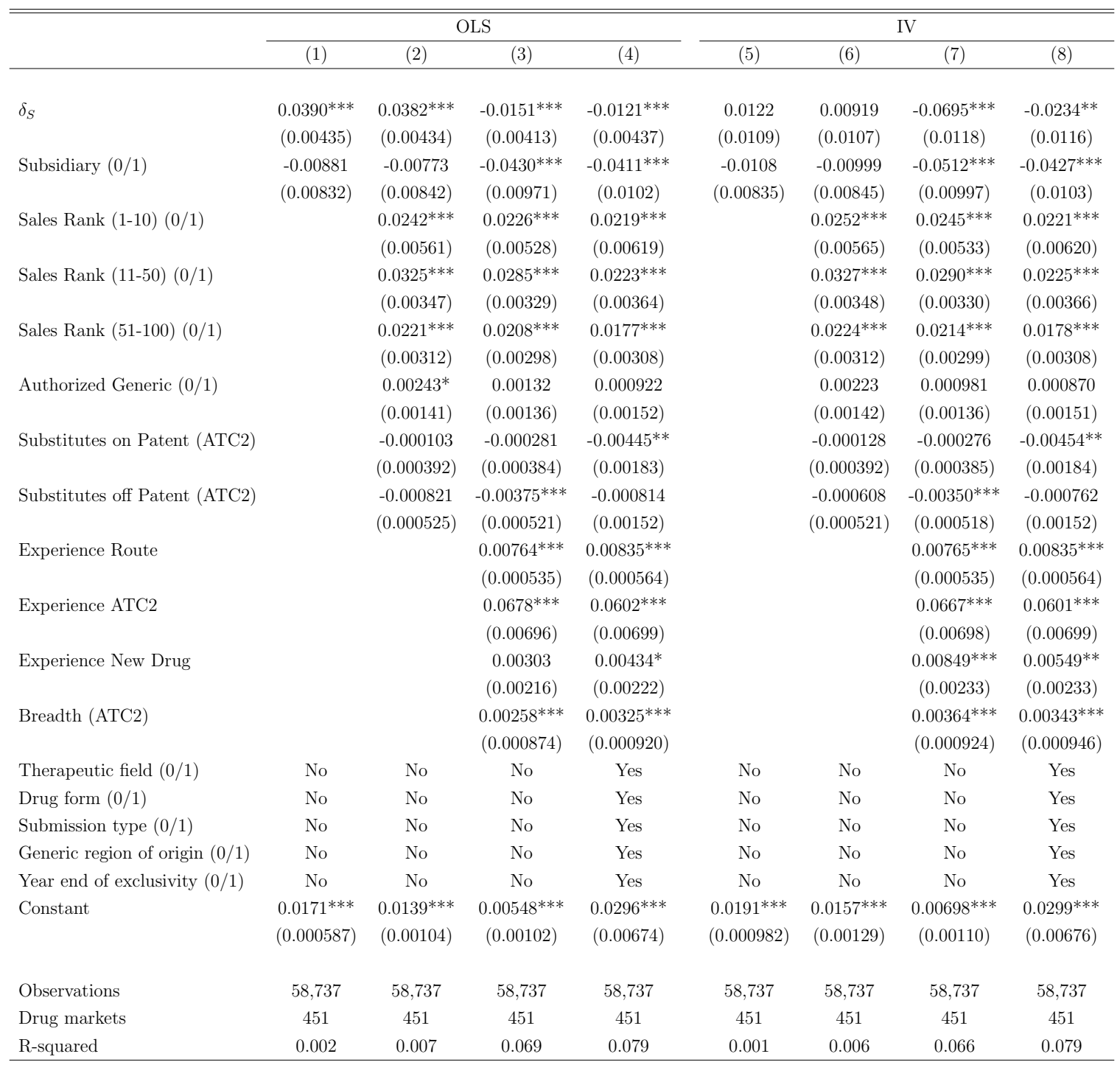

Notes: Standard errors in parentheses are robust. The dependent variable is entry within 18 months. The instruments are the number of periods listed in the ETF iShares U.S. Pharmaceutical (IHE) and an indicator variable that takes on the value 1 when the main headquarters of both companies are located in the same region. $* * * p<0.01, * * p<0.05, * p<0.1$.

\section{Table 11: Robustness - Stepwise OLS and IV $\left(\delta_{S}\right)$}




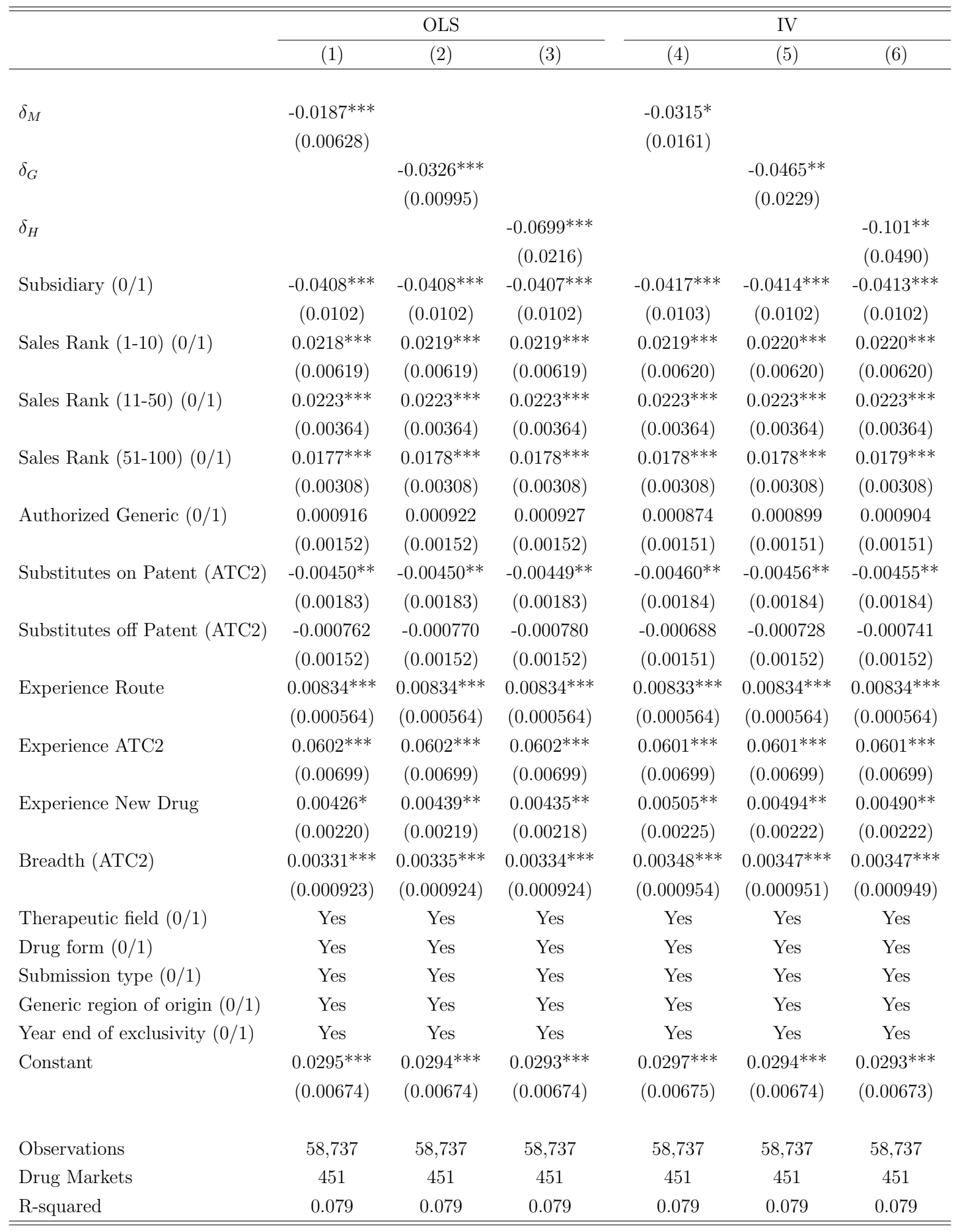

Notes: Standard errors in parentheses are robust. The dependent variable is entry within 18 months. The instruments are the number of periods listed in the ETF iShares U.S. Pharmaceutical (IHE) and an indicator variable that takes on the value 1 when the main headquarters of both companies are located in the same region. $* * * p<0.01, * * p<0.05, * p<0.1$.

\section{Table 12: Robustness - Additional measures of common ownership}




\begin{tabular}{|c|c|c|c|c|c|c|}
\hline & & OLS & & & IV & \\
\hline & $(1)$ & $(2)$ & (3) & $(4)$ & $(5)$ & $(6)$ \\
\hline$\delta_{S}$ & $\begin{array}{c}-0.0242^{* * *} \\
(0.00657)\end{array}$ & & & $\begin{array}{l}-0.0183 \\
(0.0167)\end{array}$ & & \\
\hline$\delta_{C}$ & & $\begin{array}{c}-0.0723^{* * *} \\
(0.0186)\end{array}$ & & & $\begin{array}{l}-0.0470 \\
(0.0416)\end{array}$ & \\
\hline$\delta_{L}$ & & & $\begin{array}{c}-0.0261^{* * *} \\
(0.00558)\end{array}$ & & & $\begin{array}{l}-0.0141 \\
(0.0135)\end{array}$ \\
\hline Subsidiary $(0 / 1)$ & $\begin{array}{c}-0.0722^{* * *} \\
(0.0164)\end{array}$ & $\begin{array}{c}-0.0707^{* * *} \\
(0.0164)\end{array}$ & $\begin{array}{c}-0.0714^{* * *} \\
(0.0164)\end{array}$ & $\begin{array}{c}-0.0713^{* * *} \\
(0.0165)\end{array}$ & $\begin{array}{c}-0.0700^{* * *} \\
(0.0164)\end{array}$ & $\begin{array}{c}-0.0700^{* * *} \\
(0.0164)\end{array}$ \\
\hline Sales Rank (1-10) (0/1) & $\begin{array}{c}0.0295^{* * *} \\
(0.0101)\end{array}$ & $\begin{array}{c}0.0294^{* * *} \\
(0.0101)\end{array}$ & $\begin{array}{c}0.0293^{* * *} \\
(0.0100)\end{array}$ & $\begin{array}{c}0.0293^{* * *} \\
(0.0101)\end{array}$ & $\begin{array}{c}0.0292^{* * *} \\
(0.0101)\end{array}$ & $\begin{array}{c}0.0291^{* * *} \\
(0.0101)\end{array}$ \\
\hline Sales Rank (11-50) (0/1) & $\begin{array}{c}0.0316^{* * *} \\
(0.00554)\end{array}$ & $\begin{array}{c}0.0315^{* * *} \\
(0.00553)\end{array}$ & $\begin{array}{c}0.0317^{* * *} \\
(0.00554)\end{array}$ & $\begin{array}{c}0.0315^{* * *} \\
(0.00556)\end{array}$ & $\begin{array}{c}0.0314^{* * *} \\
(0.00554)\end{array}$ & $\begin{array}{c}0.0315^{* * *} \\
(0.00555)\end{array}$ \\
\hline Sales Rank (51-100) (0/1) & $\begin{array}{c}0.0261^{* * *} \\
(0.00509)\end{array}$ & $\begin{array}{c}0.0262^{* * *} \\
(0.00509)\end{array}$ & $\begin{array}{c}0.0260^{* * *} \\
(0.00508)\end{array}$ & $\begin{array}{c}0.0260^{* * * *} \\
(0.00508)\end{array}$ & $\begin{array}{c}0.0261^{* * *} \\
(0.00508)\end{array}$ & $\begin{array}{c}0.0259^{* * *} \\
(0.00508)\end{array}$ \\
\hline Authorized Generic $(0 / 1)$ & $\begin{array}{c}0.00193 \\
(0.00266)\end{array}$ & $\begin{array}{c}0.00198 \\
(0.00266)\end{array}$ & $\begin{array}{c}0.00196 \\
(0.00266)\end{array}$ & $\begin{array}{c}0.00195 \\
(0.00265)\end{array}$ & $\begin{array}{c}0.00199 \\
(0.00265)\end{array}$ & $\begin{array}{c}0.00198 \\
(0.00265)\end{array}$ \\
\hline Substitutes on Patent (ATC2) & $\begin{array}{c}-0.00781^{* *} \\
(0.00354)\end{array}$ & $\begin{array}{c}-0.00783^{* *} \\
(0.00354)\end{array}$ & $\begin{array}{c}-0.00773^{* *} \\
(0.00354)\end{array}$ & $\begin{array}{c}-0.00776^{* *} \\
(0.00354)\end{array}$ & $\begin{array}{c}-0.00775^{* *} \\
(0.00354)\end{array}$ & $\begin{array}{c}-0.00768^{* *} \\
(0.00354)\end{array}$ \\
\hline Substitutes off Patent (ATC2) & $\begin{array}{l}-0.00340 \\
(0.00324)\end{array}$ & $\begin{array}{l}-0.00336 \\
(0.00324)\end{array}$ & $\begin{array}{l}-0.00341 \\
(0.00324)\end{array}$ & $\begin{array}{l}-0.00344 \\
(0.00323)\end{array}$ & $\begin{array}{l}-0.00342 \\
(0.00323)\end{array}$ & $\begin{array}{c}-0.00347 \\
(0.00323)\end{array}$ \\
\hline Experience Route & $\begin{array}{c}0.00822^{* * *} \\
(0.000672)\end{array}$ & $\begin{array}{c}0.00821^{* * *} \\
(0.000672)\end{array}$ & $\begin{array}{c}0.00825^{* * *} \\
(0.000673)\end{array}$ & $\begin{array}{c}0.00822^{* * *} \\
(0.000672)\end{array}$ & $\begin{array}{c}0.00822^{* * *} \\
(0.000672)\end{array}$ & $\begin{array}{c}0.00824^{* * *} \\
(0.000672)\end{array}$ \\
\hline Experience ATC2 & $\begin{array}{c}0.0632^{* * *} \\
(0.00831)\end{array}$ & $\begin{array}{c}0.0632^{* * *} \\
(0.00832)\end{array}$ & $\begin{array}{c}0.0632^{* * *} \\
(0.00831)\end{array}$ & $\begin{array}{c}0.0633^{* * *} \\
(0.00831)\end{array}$ & $\begin{array}{c}0.0633^{* * *} \\
(0.00831)\end{array}$ & $\begin{array}{c}0.0633^{* * *} \\
(0.00830)\end{array}$ \\
\hline Experience New Drug & $\begin{array}{c}0.00389 \\
(0.00293)\end{array}$ & $\begin{array}{c}0.00354 \\
(0.00287)\end{array}$ & $\begin{array}{c}0.00416 \\
(0.00290)\end{array}$ & $\begin{array}{c}0.00328 \\
(0.00314)\end{array}$ & $\begin{array}{c}0.00279 \\
(0.00296)\end{array}$ & $\begin{array}{c}0.00290 \\
(0.00302)\end{array}$ \\
\hline Breadth (ATC2) & $\begin{array}{c}0.00315^{* *} \\
(0.00158)\end{array}$ & $\begin{array}{c}0.00325^{* *} \\
(0.00159)\end{array}$ & $\begin{array}{l}0.00309^{*} \\
(0.00158)\end{array}$ & $\begin{array}{l}0.00305^{*} \\
(0.00161)\end{array}$ & $\begin{array}{c}0.00307^{*} \\
(0.00161)\end{array}$ & $\begin{array}{c}0.00293^{*} \\
(0.00159)\end{array}$ \\
\hline Therapeutic field $(0 / 1)$ & Yes & Yes & Yes & Yes & Yes & Yes \\
\hline Drug form $(0 / 1)$ & Yes & Yes & Yes & Yes & Yes & Yes \\
\hline Submission type $(0 / 1)$ & Yes & Yes & Yes & Yes & Yes & Yes \\
\hline Generic region of origin $(0 / 1)$ & Yes & Yes & Yes & Yes & Yes & Yes \\
\hline Year end of exclusivity $(0 / 1)$ & Yes & Yes & Yes & Yes & Yes & Yes \\
\hline Constant & $\begin{array}{c}0.0840^{* * *} \\
(0.0151)\end{array}$ & $\begin{array}{c}0.0826^{* * *} \\
(0.0151)\end{array}$ & $\begin{array}{c}0.0827^{* * *} \\
(0.0151)\end{array}$ & $\begin{array}{c}0.0838^{* * *} \\
(0.0151)\end{array}$ & $\begin{array}{c}0.0829^{* * *} \\
(0.0151)\end{array}$ & $\begin{array}{c}0.0830^{* * *} \\
(0.0151)\end{array}$ \\
\hline Observations & 31,979 & 31,979 & 31,979 & 31,979 & 31,979 & 31,979 \\
\hline Drug Markets & 451 & 451 & 451 & 451 & 451 & 451 \\
\hline R-squared & 0.086 & 0.086 & 0.086 & 0.086 & 0.086 & 0.086 \\
\hline
\end{tabular}

Notes: Standard errors in parentheses are robust. The dependent variable is entry within 18 months. The instruments are the number of periods listed in the ETF iShares U.S. Pharmaceutical (IHE) and an indicator variable that takes on the value 1 when the main headquarters of both companies are located in the same region. $* * * p<0.01, * * p<0.05, * p<0.1$.

Table 13: Robustness - Entrants with experience in drug form 


\begin{tabular}{|c|c|c|c|c|}
\hline & OLS & IV & Probit & Logit \\
\hline \multirow[t]{2}{*}{$\delta_{S}(0<\delta \leq 0.3)$} & -0.000349 & -0.00678 & -0.0298 & -0.0724 \\
\hline & $(0.00280)$ & $(0.00469)$ & $(0.0366)$ & $(0.0786)$ \\
\hline \multirow[t]{2}{*}{$\delta_{S}(0.3<\delta \leq 0.5)$} & $-0.00757^{*}$ & -0.00803 & $-0.127^{* *}$ & $-0.245^{* *}$ \\
\hline & $(0.00407)$ & $(0.00535)$ & $(0.0555)$ & $(0.116)$ \\
\hline \multirow[t]{2}{*}{$\delta_{S}(\delta>0.5)$} & $-0.0149^{* * *}$ & $-0.0146^{* *}$ & $-0.208^{* *}$ & $-0.488^{* * *}$ \\
\hline & $(0.00490)$ & $(0.00646)$ & $(0.0872)$ & $(0.179)$ \\
\hline \multirow[t]{2}{*}{ Subsidiary $(0 / 1)$} & $-0.0708^{* * *}$ & $-0.0731^{* * *}$ & $-0.967 * *$ & $-2.348^{* *}$ \\
\hline & $(0.0164)$ & $(0.0166)$ & $(0.489)$ & $(1.088)$ \\
\hline \multirow[t]{2}{*}{ Sales Rank (1-10) (0/1) } & $0.0294^{* * *}$ & $0.0294^{* * *}$ & $0.333^{* * *}$ & $0.805^{* * *}$ \\
\hline & $(0.0101)$ & $(0.0100)$ & $(0.0944)$ & $(0.195)$ \\
\hline \multirow[t]{2}{*}{ Sales Rank (11-50) (0/1) } & $0.0316^{* * *}$ & $0.0315^{* * *}$ & $0.346^{* * *}$ & $0.776^{* * *}$ \\
\hline & $(0.00554)$ & $(0.00553)$ & $(0.0566)$ & $(0.122)$ \\
\hline \multirow[t]{2}{*}{ Sales Rank (51-100) (0/1) } & $0.0260^{* * *}$ & $0.0262^{* * *}$ & $0.309^{* * *}$ & $0.668^{* * *}$ \\
\hline & $(0.00508)$ & $(0.00508)$ & $(0.0536)$ & $(0.114)$ \\
\hline \multirow[t]{2}{*}{ Authorized Generic $(0 / 1)$} & 0.00206 & 0.00190 & 0.0416 & 0.0700 \\
\hline & $(0.00265)$ & $(0.00265)$ & $(0.0378)$ & $(0.0817)$ \\
\hline \multirow[t]{2}{*}{ Substitutes on Patent (ATC2) } & $-0.00773^{* *}$ & $-0.00785^{* *}$ & $-0.0934^{* *}$ & $-0.173^{*}$ \\
\hline & $(0.00355)$ & $(0.00354)$ & $(0.0456)$ & $(0.0956)$ \\
\hline \multirow[t]{2}{*}{ Substitutes off Patent (ATC2) } & -0.00349 & -0.00342 & -0.0257 & -0.0614 \\
\hline & $(0.00324)$ & $(0.00323)$ & $(0.0507)$ & $(0.109)$ \\
\hline \multirow[t]{2}{*}{ Experience Route } & $0.00825^{* * *}$ & $0.00822^{* * *}$ & $0.0643^{* * *}$ & $0.126^{* * *}$ \\
\hline & $(0.000673)$ & $(0.000672)$ & $(0.00491)$ & $(0.0101)$ \\
\hline \multirow[t]{2}{*}{ Experience ATC2 } & $0.0633^{* * *}$ & $0.0632^{* * *}$ & $0.355^{* * *}$ & $0.600^{* * *}$ \\
\hline & $(0.00832)$ & $(0.00831)$ & $(0.0489)$ & $(0.100)$ \\
\hline \multirow[t]{2}{*}{ Experience New Drug } & 0.00324 & 0.00400 & $-0.107^{* * *}$ & $-0.226^{* * *}$ \\
\hline & $(0.00295)$ & $(0.00300)$ & $(0.0353)$ & $(0.0748)$ \\
\hline \multirow[t]{2}{*}{ Breadth (ATC2) } & $0.00292^{*}$ & $0.00330^{* *}$ & $0.162^{* * *}$ & $0.404^{* * *}$ \\
\hline & $(0.00160)$ & $(0.00163)$ & $(0.0195)$ & $(0.0428)$ \\
\hline Therapeutic field $(0 / 1)$ & Yes & Yes & Yes & Yes \\
\hline Drug form $(0 / 1)$ & Yes & Yes & Yes & Yes \\
\hline Submission type $(0 / 1)$ & Yes & Yes & Yes & Yes \\
\hline Generic region of origin $(0 / 1)$ & Yes & Yes & Yes & Yes \\
\hline Year end of exclusivity $(0 / 1)$ & Yes & Yes & Yes & Yes \\
\hline \multirow[t]{2}{*}{ Constant } & $0.0834^{* * *}$ & $0.0851^{* * *}$ & $-1.445^{* * *}$ & $-2.561^{* * *}$ \\
\hline & $(0.0151)$ & $(0.0152)$ & $(0.270)$ & $(0.626)$ \\
\hline Observations & 31,979 & 31,979 & 31,406 & 31,406 \\
\hline Drug markets & 451 & 451 & 451 & 451 \\
\hline R-squared & 0.086 & 0.086 & & \\
\hline
\end{tabular}

Notes: Standard errors in parentheses are robust. The dependent variable is entry within 18 months. The instruments are the number of periods listed in the ETF iShares U.S. Pharmaceutical (IHE) and an indicator variable that takes on the value 1 when the main headquarters of both companies are located in the same region. $* * * p<$ $0.01, * * p<0.05, * p<0.1$.

Table 14: Robustness - Entrants with experience in drug form 


\begin{tabular}{|c|c|c|c|c|c|c|c|c|c|}
\hline & \multicolumn{3}{|c|}{$\mathrm{Lag}=2$} & \multicolumn{3}{|c|}{$\mathrm{Lag}=1$} & \multicolumn{3}{|c|}{ Lag $=0$} \\
\hline & $(1)$ & $(2)$ & $(3)$ & $(4)$ & $(5)$ & $(6)$ & (7) & $(8)$ & $(9)$ \\
\hline$\delta_{S}$ & $\begin{array}{c}-0.0127^{* *} \\
(0.00501)\end{array}$ & & & $\begin{array}{c}-0.0121^{* * *} \\
(0.00437)\end{array}$ & & & $\begin{array}{c}-0.0127^{* * *} \\
(0.00404)\end{array}$ & & \\
\hline$\delta_{C}$ & & $\begin{array}{c}-0.0466^{* * *} \\
(0.0144)\end{array}$ & & & $\begin{array}{c}-0.0422^{* * *} \\
(0.0130)\end{array}$ & & & $\begin{array}{c}-0.0423^{* * *} \\
(0.0121)\end{array}$ & \\
\hline$\delta_{L}$ & & & $\begin{array}{c}-0.0169^{* * *} \\
(0.00469)\end{array}$ & & & $\begin{array}{c}-0.0166^{* * *} \\
(0.00400)\end{array}$ & & & $\begin{array}{c}-0.0170^{* * *} \\
(0.00369)\end{array}$ \\
\hline Subsidiary $(0 / 1)$ & $\begin{array}{c}-0.0413^{* * *} \\
(0.0118)\end{array}$ & $\begin{array}{c}-0.0410^{* * *} \\
(0.0118)\end{array}$ & $\begin{array}{c}-0.0412^{* * *} \\
(0.0118)\end{array}$ & $\begin{array}{c}-0.0411^{* * *} \\
(0.0102)\end{array}$ & $\begin{array}{c}-0.0406^{* * *} \\
(0.0102)\end{array}$ & $\begin{array}{c}-0.0411^{* * *} \\
(0.0102)\end{array}$ & $\begin{array}{c}-0.0450^{* * *} \\
(0.00896)\end{array}$ & $\begin{array}{c}-0.0443^{* * *} \\
(0.00893)\end{array}$ & $\begin{array}{c}-0.0448^{* * *} \\
(0.00894)\end{array}$ \\
\hline Sales Rank (1-10) (0/1) & $\begin{array}{c}0.0246^{* * *} \\
(0.00685)\end{array}$ & $\begin{array}{c}0.0247^{* * *} \\
(0.00685)\end{array}$ & $\begin{array}{c}0.0247^{* * *} \\
(0.00685)\end{array}$ & $\begin{array}{c}0.0219^{* * *} \\
(0.00619)\end{array}$ & $\begin{array}{c}0.0219^{* * *} \\
(0.00619)\end{array}$ & $\begin{array}{c}0.0218^{* * *} \\
(0.00619)\end{array}$ & $\begin{array}{c}0.0214^{* * *} \\
(0.00611)\end{array}$ & $\begin{array}{c}0.0215^{* * *} \\
(0.00611)\end{array}$ & $\begin{array}{c}0.0214^{* * *} \\
(0.00610)\end{array}$ \\
\hline Sales Rank (11-50) (0/1) & $\begin{array}{c}0.0229^{* * *} \\
(0.00371)\end{array}$ & $\begin{array}{c}0.0229^{* * *} \\
(0.00371)\end{array}$ & $\begin{array}{c}0.0229^{* * *} * \\
(0.00371)\end{array}$ & $\begin{array}{c}0.0223^{* * *} \\
(0.00364)\end{array}$ & $\begin{array}{c}0.0223^{* * *} \\
(0.00364)\end{array}$ & $\begin{array}{c}0.0224^{* * *} \\
(0.00364)\end{array}$ & $\begin{array}{c}0.0220^{* * *} \\
(0.00360)\end{array}$ & $\begin{array}{c}0.0220^{* * *} \\
(0.00359)\end{array}$ & $\begin{array}{c}0.0221^{* * *} \\
(0.00359)\end{array}$ \\
\hline Sales Rank (51-100) (0/1) & $\begin{array}{c}0.0153^{* * *} \\
(0.00324)\end{array}$ & $\begin{array}{c}0.0153^{* * *} \\
(0.00324)\end{array}$ & $\begin{array}{c}0.0153^{\text {*** }} \\
(0.00324)\end{array}$ & $\begin{array}{c}0.0177^{* * *} \\
(0.00308)\end{array}$ & $\begin{array}{c}0.0178^{* * *} \\
(0.00308)\end{array}$ & $\begin{array}{c}0.0177^{* * *} \\
(0.00308)\end{array}$ & $\begin{array}{c}0.0174^{* * *} \\
(0.00304)\end{array}$ & $\begin{array}{c}0.0175^{* * *} \\
(0.00304)\end{array}$ & $\begin{array}{c}0.0174^{* * *} \\
(0.00304)\end{array}$ \\
\hline Authorized Generic $(0 / 1)$ & $\begin{array}{l}0.000957 \\
(0.00157)\end{array}$ & $\begin{array}{l}0.000936 \\
(0.00157)\end{array}$ & $\begin{array}{l}0.000947 \\
(0.00157)\end{array}$ & $\begin{array}{l}0.000922 \\
(0.00152)\end{array}$ & $\begin{array}{c}0.000928 \\
(0.00152)\end{array}$ & $\begin{array}{c}0.000930 \\
(0.00152)\end{array}$ & $\begin{array}{l}0.000863 \\
(0.00150)\end{array}$ & $\begin{array}{l}0.000838 \\
(0.00150)\end{array}$ & $\begin{array}{l}0.000858 \\
(0.00150)\end{array}$ \\
\hline Substitutes on Patent (ATC2) & $\begin{array}{c}-0.00394^{* *} \\
(0.00198)\end{array}$ & $\begin{array}{c}-0.00397^{* *} \\
(0.00198)\end{array}$ & $\begin{array}{c}-0.00391^{* *} \\
(0.00198)\end{array}$ & $\begin{array}{c}-0.00445^{* *} \\
(0.00183)\end{array}$ & $\begin{array}{c}-0.00448^{* *} \\
(0.00183)\end{array}$ & $\begin{array}{c}-0.00444^{* *} \\
(0.00183)\end{array}$ & $\begin{array}{c}-0.00427^{* *} \\
(0.00181)\end{array}$ & $\begin{array}{c}-0.00427^{* *} \\
(0.00181)\end{array}$ & $\begin{array}{c}-0.00429^{* *} \\
(0.00180)\end{array}$ \\
\hline Substitutes off Patent (ATC2) & $\begin{array}{l}-0.00177 \\
(0.00175)\end{array}$ & $\begin{array}{l}-0.00177 \\
(0.00175)\end{array}$ & $\begin{array}{l}-0.00179 \\
(0.00175)\end{array}$ & $\begin{array}{c}-0.000814 \\
(0.00152)\end{array}$ & $\begin{array}{r}-0.000788 \\
(0.00152)\end{array}$ & $\begin{array}{c}-0.000827 \\
(0.00152)\end{array}$ & $\begin{array}{l}-0.000827 \\
(0.00150)\end{array}$ & $\begin{array}{r}-0.000786 \\
(0.00150)\end{array}$ & $\begin{array}{r}-0.000839 \\
(0.00150)\end{array}$ \\
\hline Experience Route & $\begin{array}{c}0.00812^{* * *} \\
(0.000570)\end{array}$ & $\begin{array}{c}0.00812^{\text {*** }} \\
(0.000570)\end{array}$ & $\begin{array}{c}0.00813^{* * *} \\
(0.000570)\end{array}$ & $\begin{array}{c}0.00835^{* * *} \\
(0.000564)\end{array}$ & $\begin{array}{c}0.00834^{* * *} \\
(0.000564)\end{array}$ & $\begin{array}{c}0.00836^{* * *} \\
(0.000564)\end{array}$ & $\begin{array}{c}0.00830^{* * *} \\
(0.000564)\end{array}$ & $\begin{array}{c}0.00830^{* * *} \\
(0.000564)\end{array}$ & $\begin{array}{c}0.00832^{\text {*** }} \\
(0.000565)\end{array}$ \\
\hline Experience ATC2 & $\begin{array}{c}0.0593^{* * *} \\
(0.00702)\end{array}$ & $\begin{array}{c}0.0592^{* * *} \\
(0.00702)\end{array}$ & $\begin{array}{c}0.0591^{* * * *} \\
(0.00702)\end{array}$ & $\begin{array}{c}0.0602^{* * *} \\
(0.00699)\end{array}$ & $\begin{array}{c}0.0602^{* * *} \\
(0.00699)\end{array}$ & $\begin{array}{c}0.0601^{* * *} \\
(0.00699)\end{array}$ & $\begin{array}{c}0.0604^{* * *} \\
(0.00700)\end{array}$ & $\begin{array}{c}0.0604^{* * *} \\
(0.00700)\end{array}$ & $\begin{array}{c}0.0603^{* * *} \\
(0.00699)\end{array}$ \\
\hline Experience New Drug & $\begin{array}{c}0.00553^{* *} \\
(0.00225)\end{array}$ & $\begin{array}{c}0.00564^{* *} \\
(0.00221)\end{array}$ & $\begin{array}{c}0.00587^{* * *} \\
(0.00223)\end{array}$ & $\begin{array}{l}0.00434^{*} \\
(0.00222)\end{array}$ & $\begin{array}{c}0.00431^{* *} \\
(0.00217)\end{array}$ & $\begin{array}{c}0.00475^{* *} \\
(0.00219)\end{array}$ & $\begin{array}{l}0.00425^{*} \\
(0.00221)\end{array}$ & $\begin{array}{c}0.00415^{*} \\
(0.00217)\end{array}$ & $\begin{array}{c}0.00466^{* *} \\
(0.00219)\end{array}$ \\
\hline Breadth (ATC2) & $\begin{array}{c}0.00235^{* *} \\
(0.000936)\end{array}$ & $\begin{array}{c}0.00244^{* * *} \\
(0.000938)\end{array}$ & $\begin{array}{c}0.00239^{* *} \\
(0.000935)\end{array}$ & $\begin{array}{c}0.00325^{* * *} \\
(0.000920)\end{array}$ & $\begin{array}{c}0.00333^{* * *} \\
(0.000924)\end{array}$ & $\begin{array}{c}0.00329^{* * *} \\
(0.000920)\end{array}$ & $\begin{array}{c}0.00336^{* * *} \\
(0.000920)\end{array}$ & $\begin{array}{c}0.00345^{* * *} \\
(0.000923)\end{array}$ & $\begin{array}{c}0.00340^{* * *} \\
(0.000920)\end{array}$ \\
\hline Therapeutic field $(0 / 1)$ & Yes & Yes & Yes & Yes & Yes & Yes & Yes & Yes & Yes \\
\hline Drug form $(0 / 1)$ & Yes & Yes & Yes & Yes & Yes & Yes & Yes & Yes & Yes \\
\hline Submission type $(0 / 1)$ & Yes & Yes & Yes & Yes & Yes & Yes & Yes & Yes & Yes \\
\hline Generic region of origin $(0 / 1)$ & Yes & Yes & Yes & Yes & Yes & Yes & Yes & Yes & Yes \\
\hline Year end of exclusivity $(0 / 1)$ & Yes & Yes & Yes & Yes & Yes & Yes & Yes & Yes & Yes \\
\hline Constant & $\begin{array}{c}0.0214^{* * *} \\
(0.00736)\end{array}$ & $\begin{array}{c}0.0211^{* * *} \\
(0.00736)\end{array}$ & $\begin{array}{c}0.0210^{* * *} \\
(0.00735)\end{array}$ & $\begin{array}{c}0.0296^{* * *} \\
(0.00674)\end{array}$ & $\begin{array}{c}0.00333^{* * *} \\
(0.000924)\end{array}$ & $\begin{array}{c}0.0292^{* * *} \\
(0.00674)\end{array}$ & $\begin{array}{c}0.0287^{* * *} \\
(0.00665)\end{array}$ & $\begin{array}{c}0.0282^{* * *} \\
(0.00664)\end{array}$ & $\begin{array}{c}0.0283^{* * *} \\
(0.00664)\end{array}$ \\
\hline Observations & 54,035 & 54,035 & 54,035 & 58,737 & 58,737 & 58,737 & 59,390 & 59,390 & 59,390 \\
\hline Drug Markets & 415 & 415 & 415 & 451 & 451 & 451 & 451 & 451 & 451 \\
\hline R-squared & 0.078 & 0.078 & 0.078 & 0.079 & 0.079 & 0.079 & 0.079 & 0.079 & 0.080 \\
\hline
\end{tabular}

Table 15: Robustness - Common ownership measured 2, 1 and 0 years before end of exclusivity (OLS) 


\begin{tabular}{|c|c|c|c|c|c|c|c|c|c|}
\hline & \multicolumn{3}{|c|}{$\mathrm{Lag}=2$} & \multicolumn{3}{|c|}{$\mathrm{Lag}=1$} & \multicolumn{3}{|c|}{$\mathrm{Lag}=0$} \\
\hline & (1) & $(2)$ & $(3)$ & (4) & $(5)$ & (6) & $(7)$ & $(8)$ & (9) \\
\hline$\delta_{S}$ & $\begin{array}{c}-0.0393^{* * *} \\
(0.0140)\end{array}$ & & & $\begin{array}{c}-0.0234^{* *} \\
(0.0116)\end{array}$ & & & $\begin{array}{l}-0.0164 \\
(0.0104)\end{array}$ & & \\
\hline$\delta_{C}$ & & $\begin{array}{c}-0.0972^{* * *} \\
(0.0341)\end{array}$ & & & $\begin{array}{c}-0.0601^{* *} \\
(0.0291)\end{array}$ & & & $\begin{array}{c}-0.0436^{*} \\
(0.0264)\end{array}$ & \\
\hline$\delta_{L}$ & & & $\begin{array}{c}-0.0327^{* * *} \\
(0.0118)\end{array}$ & & & $\begin{array}{c}-0.0187^{* *} \\
(0.00952)\end{array}$ & & & $\begin{array}{c}-0.0132 \\
(0.00863)\end{array}$ \\
\hline Subsidiary $(0 / 1)$ & $\begin{array}{c}-0.0447^{* * *} \\
(0.0119)\end{array}$ & $\begin{array}{c}-0.0425^{* * *} \\
(0.0118)\end{array}$ & $\begin{array}{c}-0.0426^{* * *} \\
(0.0118)\end{array}$ & $\begin{array}{c}-0.0427^{* * *} \\
(0.0103)\end{array}$ & $\begin{array}{c}-0.0412^{* * *} \\
(0.0102)\end{array}$ & $\begin{array}{c}-0.0413^{* * *} \\
(0.0102)\end{array}$ & $\begin{array}{c}-0.0456^{* * *} \\
(0.00906)\end{array}$ & $\begin{array}{c}-0.0444^{* * *} \\
(0.00894)\end{array}$ & $\begin{array}{c}-0.0444^{* * *} \\
(0.00895)\end{array}$ \\
\hline Sales Rank (1-10) (0/1) & $\begin{array}{c}0.0248^{* * *} \\
(0.00685)\end{array}$ & $\begin{array}{c}0.0249^{* * *} \\
(0.00685)\end{array}$ & $\begin{array}{c}0.0248^{* * *} \\
(0.00685)\end{array}$ & $\begin{array}{c}0.0221^{* * *} \\
(0.00620)\end{array}$ & $\begin{array}{c}0.0220^{* * *} \\
(0.00620)\end{array}$ & $\begin{array}{c}0.0218^{* * *} \\
(0.00619)\end{array}$ & $\begin{array}{c}0.0215^{* * *} \\
(0.00612)\end{array}$ & $\begin{array}{c}0.0215^{* * *} \\
(0.00611)\end{array}$ & $\begin{array}{c}0.0214 * * * \\
(0.00611)\end{array}$ \\
\hline Sales Rank (11-50) (0/1) & $\begin{array}{c}0.0232^{* * *} \\
(0.00373)\end{array}$ & $\begin{array}{c}0.0230 * * * \\
(0.00372)\end{array}$ & $\begin{array}{c}0.0231^{* * *} \\
(0.00372)\end{array}$ & $\begin{array}{c}0.0225^{* * *} \\
(0.00366)\end{array}$ & $\begin{array}{c}0.0224^{* * *} \\
(0.00365)\end{array}$ & $\begin{array}{c}0.0224^{* * *} \\
(0.00365)\end{array}$ & $\begin{array}{c}0.0221^{* * *} \\
(0.00361)\end{array}$ & $\begin{array}{c}0.0220^{* * *} \\
(0.00360)\end{array}$ & $\begin{array}{c}0.0220 * * * \\
(0.00360)\end{array}$ \\
\hline Sales Rank (51-100) (0/1) & $\begin{array}{c}0.0154^{* * *} \\
(0.00324)\end{array}$ & $\begin{array}{c}0.0155^{* * *} \\
(0.00324)\end{array}$ & $\begin{array}{c}0.0153^{* * *} \\
(0.00324)\end{array}$ & $\begin{array}{c}0.0178^{* * *} \\
(0.00308)\end{array}$ & $\begin{array}{c}0.0179^{* * *} \\
(0.00308)\end{array}$ & $\begin{array}{c}0.0177^{* * *} \\
(0.00308)\end{array}$ & $\begin{array}{c}0.0174^{* * *} \\
(0.00303)\end{array}$ & $\begin{array}{c}0.0175^{* * *} \\
(0.00303)\end{array}$ & $\begin{array}{c}0.0174^{* * *} \\
(0.00303)\end{array}$ \\
\hline Authorized Generic $(0 / 1)$ & $\begin{array}{l}0.000851 \\
(0.00157)\end{array}$ & $\begin{array}{l}0.000857 \\
(0.00157)\end{array}$ & $\begin{array}{l}0.000890 \\
(0.00157)\end{array}$ & $\begin{array}{l}0.000870 \\
(0.00151)\end{array}$ & $\begin{array}{l}0.000907 \\
(0.00151)\end{array}$ & $\begin{array}{l}0.000924 \\
(0.00151)\end{array}$ & $\begin{array}{l}0.000849 \\
(0.00150)\end{array}$ & $\begin{array}{c}0.000836 \\
(0.00150)\end{array}$ & $\begin{array}{l}0.000870 \\
(0.00150)\end{array}$ \\
\hline Substitutes on Patent (ATC2) & $\begin{array}{c}-0.00415^{* *} \\
(0.00198)\end{array}$ & $\begin{array}{c}-0.00412^{* *} \\
(0.00198)\end{array}$ & $\begin{array}{c}-0.00398^{* *} \\
(0.00198)\end{array}$ & $\begin{array}{c}-0.00454^{* *} \\
(0.00184)\end{array}$ & $\begin{array}{c}-0.00453^{* *} \\
(0.00183)\end{array}$ & $\begin{array}{c}-0.00445^{* *} \\
(0.00183)\end{array}$ & $\begin{array}{c}-0.00429^{* *} \\
(0.00181)\end{array}$ & $\begin{array}{c}-0.00428^{* *} \\
(0.00181)\end{array}$ & $\begin{array}{c}-0.00427^{* *} \\
(0.00181)\end{array}$ \\
\hline Substitutes off Patent (ATC2) & $\begin{array}{l}-0.00194 \\
(0.00176)\end{array}$ & $\begin{array}{l}-0.00186 \\
(0.00175)\end{array}$ & $\begin{array}{l}-0.00189 \\
(0.00175)\end{array}$ & $\begin{array}{r}-0.000762 \\
(0.00152)\end{array}$ & $\begin{array}{r}-0.000753 \\
(0.00152)\end{array}$ & $\begin{array}{l}-0.000821 \\
(0.00152)\end{array}$ & $\begin{array}{r}-0.000808 \\
(0.00150)\end{array}$ & $\begin{array}{c}-0.000783 \\
(0.00150)\end{array}$ & $\begin{array}{l}-0.000852 \\
(0.00150)\end{array}$ \\
\hline Experience Route & $\begin{array}{c}0.00813^{* * *} \\
(0.000569)\end{array}$ & $\begin{array}{c}0.00811^{* * *} \\
(0.000569)\end{array}$ & $\begin{array}{c}0.00814^{* * *} \\
(0.000569)\end{array}$ & $\begin{array}{c}0.00835^{* * *} \\
(0.000564)\end{array}$ & $\begin{array}{c}0.00834^{* * *} \\
(0.000564)\end{array}$ & $\begin{array}{c}0.00836^{* * *} \\
(0.000564)\end{array}$ & $\begin{array}{c}0.00830^{* * *} \\
(0.000564)\end{array}$ & $\begin{array}{c}0.00830^{* * *} \\
(0.000564)\end{array}$ & $\begin{array}{c}0.00832^{\text {*** }} \\
(0.000564)\end{array}$ \\
\hline Experience ATC2 & $\begin{array}{c}0.0591^{* * * *} \\
(0.00702)\end{array}$ & $\begin{array}{c}0.0590^{* * *} \\
(0.00702)\end{array}$ & $\begin{array}{c}0.0589^{* * *} \\
(0.00702)\end{array}$ & $\begin{array}{c}0.0601^{* * *} \\
(0.00699)\end{array}$ & $\begin{array}{c}0.0601^{* * *} \\
(0.00699)\end{array}$ & $\begin{array}{c}0.0601^{* * *} \\
(0.00699)\end{array}$ & $\begin{array}{c}0.0604^{* * *} \\
(0.00700)\end{array}$ & $\begin{array}{c}0.0604^{* * *} \\
(0.00700)\end{array}$ & $\begin{array}{c}0.0604^{* * *} \\
(0.00700)\end{array}$ \\
\hline Experience New Drug & $\begin{array}{c}0.00809^{* * *} \\
(0.00244)\end{array}$ & $\begin{array}{c}0.00709^{* * *} \\
(0.00229)\end{array}$ & $\begin{array}{c}0.00734^{* * *} \\
(0.00233)\end{array}$ & $\begin{array}{c}0.00549^{* *} \\
(0.00233)\end{array}$ & $\begin{array}{c}0.00483^{* *} \\
(0.00221)\end{array}$ & $\begin{array}{c}0.00496^{* *} \\
(0.00224)\end{array}$ & $\begin{array}{c}0.00463^{* *} \\
(0.00227)\end{array}$ & $\begin{array}{c}0.00418^{*} \\
(0.00218)\end{array}$ & $\begin{array}{l}0.00427^{*} \\
(0.00220)\end{array}$ \\
\hline Breadth (ATC2) & $\begin{array}{c}0.00273^{* * *} \\
(0.000963)\end{array}$ & $\begin{array}{c}0.00274^{* * *} \\
(0.000963)\end{array}$ & $\begin{array}{c}0.00259^{* * *} \\
(0.000953)\end{array}$ & $\begin{array}{c}0.00343^{* * *} \\
(0.000946)\end{array}$ & $\begin{array}{c}0.00345^{* * *} \\
(0.000947)\end{array}$ & $\begin{array}{c}0.00332^{* * *} \\
(0.000935)\end{array}$ & $\begin{array}{c}0.00343^{* * *} \\
(0.000943)\end{array}$ & $\begin{array}{c}0.00346^{* * *} \\
(0.000945)\end{array}$ & $\begin{array}{c}0.00335^{\text {*** }} \\
(0.000933)\end{array}$ \\
\hline Therapeutic field $(0 / 1)$ & Yes & Yes & Yes & Yes & Yes & Yes & Yes & Yes & Yes \\
\hline Drug form $(0 / 1)$ & Yes & Yes & Yes & Yes & Yes & Yes & Yes & Yes & Yes \\
\hline Submission type $(0 / 1)$ & Yes & Yes & Yes & Yes & Yes & Yes & Yes & Yes & Yes \\
\hline Generic region of origin $(0 / 1)$ & Yes & Yes & Yes & Yes & Yes & Yes & Yes & Yes & Yes \\
\hline Year end of exclusivity $(0 / 1)$ & Yes & Yes & Yes & Yes & Yes & Yes & Yes & Yes & Yes \\
\hline Constant & $\begin{array}{c}0.0223^{* * *} \\
(0.00739)\end{array}$ & $\begin{array}{c}0.0213^{* * *} \\
(0.00736)\end{array}$ & $\begin{array}{c}0.0210^{* * *} \\
(0.00735)\end{array}$ & $\begin{array}{c}0.0299^{* * *} \\
(0.00676)\end{array}$ & $\begin{array}{c}0.00345^{* * *} \\
(0.000947)\end{array}$ & $\begin{array}{c}0.0292^{* * *} \\
(0.00673)\end{array}$ & $\begin{array}{c}0.0287^{* * *} \\
(0.00665)\end{array}$ & $\begin{array}{c}0.0282^{* * *} \\
(0.00663)\end{array}$ & $\begin{array}{c}0.0283^{* * *} \\
(0.00663)\end{array}$ \\
\hline Observations & 54,035 & 54,035 & 54,035 & 58,737 & 58,737 & 58,737 & 59,390 & 59,390 & 59,390 \\
\hline Drug Markets & 415 & 415 & 415 & 451 & 451 & 451 & 451 & 451 & 451 \\
\hline R-squared & 0.078 & 0.078 & 0.078 & 0.079 & 0.079 & 0.079 & 0.079 & 0.079 & 0.080 \\
\hline
\end{tabular}

Table 16: Robustness - Common ownership measured 2, 1 and 0 years before end of exclusivity (IV) 